\title{
ACCELERATED SWELL TESTING OF ARTIFICIAL SULFATE BEARING LIME STABILISED COHESIVE SOILS
}

\author{
A.J. Buttress*, J.A. Grenfell, and G.D. Airey. \\ *- corresponding author, Nottingham Transportation Engineering Centre (NTEC), \\ The University of Nottingham, University Park, Nottingham, NG7 2RD. \\ Email address: adam.buttress@nottingham.ac.uk
}

\section{Abstract}

This paper reports on the physico-chemical response of two lime stabilised sulfate bearing artificial soils subject to the European Accelerated Volumetric Swell Test (EN13286-49). At various intervals during the test, a specimen was removed and subject to compositional and microstructural analysis. Ettringite was formed by both soils types, but with significant differences in crystal morphology. Ettringite crystals formed from kaolin based soils were very small, colloidal in size and tended to form on the surface of other particles. Conversely, those formed from montmorillonite were relatively large and typically formed away from the surface in the pore solution. It was concluded that the mechanism by which ettringite forms is determined by the hydroxide ion concentration in the pore solution and the fundamental structure of the bulk clay. In the kaolin soil, ettringite forms by a topochemical mechanism and expands by crystal swelling. In the montmorillonite soil, it forms by a through-solution mechanism and crystal growth.

\section{Introduction}

Soil stabilisation is a useful civil engineering technique that allows the in-situ ground to be incorporated into an engineered structure. One of the major deleterious processes that affect stabilised soils is sulfate heave. This occurs when sulfate minerals already present in the soil or transported there by mobile ground water, react with the lime and/or cement used in the stabilisation along with alumina from dissolved clay particles to form expansive calcium sulfo-aluminate hydrate. The principal expansive mineral is called Ettringite. When ettringite forms after the stabilised layer has been mixed and compacted, it exerts pressure on the soil, because it has a greater unit volume than the reactants it was derived from [1]. This results in volumetric expansion known as sulfate heave and causes significant damage to the entire pavement structure, which can manifest itself as both transverse and longitudal ridges and cracks in the pavement surface, as well as discreet areas where the strength loss in the foundation is so severe that significant permanent deformation can occur [2-9]. 
In these case studies, the use of lime $(\mathrm{CaO})$, slaked lime $\left(\mathrm{Ca}(\mathrm{OH})_{2}\right)$ or cement, provided conditions that were sufficiently alkaline, to promote the dissolution of reactive alumina. The formation of expansive calcium sulfoaluminates, was promoted by sufficient quantities of water entering the stabilised layer. The binder addition was of sufficient quantity to maintain the necessary alkaline conditions, so that they also remained stable enough to cause expansion and damage to the pavement.

The formation of ettringite proceeds firstly on the dissolution of slaked lime (1). The resulting increase in $\mathrm{pH}$ to $\mathrm{pH}>12$, then solubilised the alumina-silicates into the pore solution (2):

$$
\mathrm{Ca}(\mathrm{OH})_{2} \rightarrow \mathrm{Ca}^{2+}+2(\mathrm{OH})^{-}
$$

$\mathrm{Al}_{2} \mathrm{Si}_{4} \mathrm{O}_{10}(\mathrm{OH})_{2} \cdot n \mathrm{H}_{2} \mathrm{O}+2(\mathrm{OH})^{-}+10 \mathrm{H}_{2} \mathrm{O} \rightarrow 2\left[2 \mathrm{Al}(\mathrm{OH})_{4}^{-}+4 \mathrm{H}_{4} \mathrm{SiO}_{4}\right]+n \mathrm{H}_{2} \mathrm{O}$

The aluminate ions - $\mathrm{Al}(\mathrm{OH})_{4}{ }^{-}$react with sulfate ions from the dissolution of gypsum (3) to form ettringite shown in (4):

$$
\begin{aligned}
& \mathrm{CaSO}_{4} \cdot 2 \mathrm{H}_{2} \mathrm{O} \rightarrow 2 \mathrm{Ca}^{2+}+\mathrm{SO}_{4}{ }^{2-}+2 \mathrm{H}_{2} \mathrm{O} \\
& 6 \mathrm{Ca}^{2+}+2 \mathrm{Al}(\mathrm{OH})_{4}^{-}+4 \mathrm{OH}^{-}+3 \mathrm{SO}_{4}{ }^{2-}+26 \mathrm{H}_{2} \mathrm{O} \rightarrow \mathrm{Ca}_{6}\left[\mathrm{Al}(\mathrm{OH})_{6}\right]_{2} \cdot\left(\mathrm{SO}_{4}\right)_{3} \cdot 26 \mathrm{H}_{2} \mathrm{O}
\end{aligned}
$$

Using molar calculations of the simple ettringite precipitation reaction (5) and known surface area values, Little et al [1] predicted that when sulfate concentration is the limiting factor in the soil system, the relationship between soluble sulfates and ettringite formation is linear. Considering the formation of AFt from $\mathrm{C}_{3} \mathrm{~A}$, both Basista \& Weglewski [10] and [1] used simple calculations for component molar masses (6) and corresponding molar volumes (7) to estimate the degree of expansion:

$$
\begin{aligned}
& 3 \mathrm{CaO} \cdot \mathrm{Al}_{2} \mathrm{O}_{3}+3 \mathrm{CaSO}_{4}+26 \mathrm{H}_{2} \mathrm{O} \leftrightarrow \mathrm{Ca}_{6} \mathrm{Al}_{2}\left(\mathrm{SO}_{4}\right)_{3}(\mathrm{OH})_{12} \cdot 26 \mathrm{H}_{2} \mathrm{O} \\
& \text { mass }(\mathrm{g} / \mathrm{mol}) \quad 270.2+(3 \times 172.1)+(26 \times 18.0)=+1254.5 \mathrm{gmol}^{-1} \\
& \text { volume }\left(\mathrm{cm}^{3} / \mathrm{mol}\right) \quad 88.8+(3 \times 71.1)+(26 \times 18.0)=+725.1 \mathrm{~cm}^{3} \mathrm{~mol}^{-1}
\end{aligned}
$$

Expansion in this system only occurs when the water consumed during ettringite formation comes from an external source [1]. That is, outside the localised cementitious matrix. The volume occupied by the precipitated ettringite is much greater than that volume occupied by the reactant soil components and results in a positive volumetric change (swelling).

Recent European harmonisation of test standards has seen the slight modification of BS1924-2 into EN 13286-47 [11], although the procedure and pass/fail criteria remain largely unchanged. UK practitioners also have the option of using the less well known European accelerated swell test (EN 13286-49 [12]), in which 3-dimensional swell is measured on relatively small specimens, completely exposed to water on all sides, at elevated temperatures. This has the advantage of reducing the time 
taken to test the specimens. In the United Kingdom (UK) linear soaked California Bearing Ratio (CBR) swell test, this takes a minimum of 31 days (including preparation and curing time), whereas the European Accelerated volumetric swell test takes only 10 days. However, UK practioners have little experience of using this test as historically, the soaked CBR test has been used [13]. Previous work has shown that there are significant differences in a soils swelling response when subjected to EN13286-49 compared to BS1924-2 [14].

This paper reports the study on the physicochemical behaviour of two lime stabilised cohesive soils, subject to the European Accelerated Volumetric Swell Test [12]. The aim of this work is to gain understanding of how the conditions imposed by the accelerated swell test cause the associated change in dimensional stability and the underlying chemical composition

\section{Methodology}

\section{Materials}

Artificial soils were used in this study so that there absolute composition could be known and any observed physicochemical effect be related back to the composition of the soil under test. The soils used were produced in the laboratory based on kaolinite and smectite (montmorillonite in this case) clays. These clays have differing fundamental structure with the kaolinite having a 1:1 layer structure and the montmorillonite having a 2:1 layer structure [15, 16]. These have been shown to exhibit behaviour that is markedly different in terms of both macro-physical and chemical characteristics when subject to stabilisation [2].

Table 1 shows the composition of the blended artificial soils. The soils were a blend of clay (from a commercially available product), sand and gypsum, which were subsequently stabilised with lime. In the case of the montmorillonite mix, the clay and sulfate content were fixed and the mix ratio adjusted for the amount of binder required by reducing the percentage sand.

Table 1: Dry mix proportions of the artificial soils

\begin{tabular}{|c|c|c|c|c|c|c|c|}
\hline Mix ID & $\begin{array}{c}\text { Clay } \\
\text { Type }\end{array}$ & \% Clay & \% Sand & $\begin{array}{c}\% \\
\text { Sulfate } \\
(\mathbf{a s ~ S O})_{3}\end{array}$ & $\begin{array}{c}\% \\
\text { Binder } \\
(\mathbf{C a O})\end{array}$ & $\begin{array}{c}\text { OWC+2* } \\
(\%)\end{array}$ & $\begin{array}{c}\mathbf{M D D}^{* \star} \\
\left(\mathbf{M g}^{3} \mathbf{m}^{3}\right.\end{array}$ \\
\hline K4L5S & $\mathrm{K}$ & 60.0 & 31.0 & 5.0 & 4.0 & 21.5 & 1.70 \\
\hline M6L5S & $\mathrm{M}$ & 60.0 & 29.0 & 5.0 & 6.0 & 22.5 & 1.66 \\
\hline
\end{tabular}

Note: $\mathrm{K}$ - kaolin, $\mathrm{M}$ - montmorillonite, ${ }^{*}$ - Optimum Water Content (OWC), MDD - Maximum dry density $\left(\mathrm{Mg} / \mathrm{m}^{3}\right)$, $\dagger^{\dagger}$ - assumed based on results from high sulfate mix.

The soils were designed to represent a 'worst case' stabilisation scenario. The clay content is around the upper bounds as reported in a survey of UK soils [17]. A 5\% sulfate content is generally accepted as very or too high for lime stabilisation and would require alternative methods if used in practice. It 
was chosen here so that physicochemical changes as a function of soil composition and immersion time could be differentiated. Note that in order to achieve a target sulfate content (as $\% \mathrm{SO}_{3}$ ) of $5.0 \%$ the actual amount of gypsum added was necessarily higher by a factor of $2.15\left(\mathrm{M}_{\mathrm{r}} \mathrm{CaSO}_{4} 2 \mathrm{H}_{2} \mathrm{O} / \mathrm{M}_{\mathrm{r}}\right.$ $\mathrm{SO}_{3}$ ). Therefore the actual modal composition of each soil is given in Table 2 .

Table 2: Modal composition of the artificial soils

\begin{tabular}{|c|c|c|c|c|c|c|c|}
\hline \multirow{2}{*}{ Mix ID } & \multicolumn{7}{|c|}{ Mineralogical Composition (\%) } \\
\cline { 2 - 8 } & $\begin{array}{c}\text { Calcium } \\
\text { Bentonite }\end{array}$ & Kaolin & Potash Mica & Soda Mica & Quartz & Lime & Gypsum \\
\hline K4L5S & - & 33.3 & 17.2 & 1.2 & 33.7 & 4 & 10.8 \\
\hline M6L5S & 55.3 & - & - & - & 28.5 & 6 & 10.8 \\
\hline
\end{tabular}

The kaolin was supplied by Sibelco UK as Powdered China Clay under the trade name Puraflo S. The montmorillonite as Calcium Bentonite and quartz sand (Chelford 14/25) was supplied by RS Minerals. The lime was used as calcium oxide supplied by URS Corp. Compositional analysis by X-Ray Fluorescence (XRF) has been presented previously in [14].

The soils were produced by first dry mixing the clay, sand and gypsum together in a rotary drum mixer. Demineralised water was then added to the optimum water content and left to condition, covered with a polyethylene sheet to prevent moisture loss for approximately 1 hour. The wet mix was the stirred and the calcium oxide binder slowly added. The soil mixture was then left to condition for $24 \pm 1 \mathrm{~h}$ at $20^{\circ} \mathrm{C}$ prior to manufacture of the test specimens.

The gypsum was supplied by Saint Gobain. It was supplied as crushed gypsum stone direct from the quarrying operation in Linconshire. This was prepared by drying at room temperature to remove surface water, then sieved to remove trace impurities of mudstone. The gypsum was passed through a jaw crusher, and then sieved again. The material passing the $425 \mu \mathrm{m}$ sieve was retained for use in the study. Confirmation that the material was the dihydrate was obtained by TGA. This along with the XRF was used to determine the purity of the material at $97.3 \% \mathrm{w} / \mathrm{w} \mathrm{CaSO}_{4} \cdot 2 \mathrm{H}_{2} \mathrm{O}$. The purity of the lime was also determined by TGA at $95.6 \% \mathrm{w} / \mathrm{w} \mathrm{CaO}$

Also determined was the carbonate impurity content of $0.98 \% \mathrm{w} / \mathrm{w} \mathrm{CaCO}_{3}$ and $3.45 \% \mathrm{w} / \mathrm{w} \mathrm{Ca}(\mathrm{OH})_{2}$. This differs from the XRF analysis, where $\mathrm{CaO}$ content was determined as $86 \%$. The handling of the material on sample preparation may have introduced moisture to the sample increasing the $\mathrm{Ca}(\mathrm{OH})_{2}$ content, which is inferred by the Loss On Ignition (LOI) of $11.7 \%$.

\section{Swell Test Procedure - European Accelerated Volumetric Swell Test (EN 13286-49)}

This standard requires a set of three $50 \mathrm{~mm}$ diameter $\times 50 \mathrm{~mm}$ high specimens to be produced to $96 \pm 0.5 \%$ of the "Normal Proctor" wet density, manufactured using axial compression. The specimens 
must be manufactured using material passing the $6.3 \mathrm{~mm}$ sieve. They are then stored at $20 \pm 2{ }^{\circ} \mathrm{C}$ at more than $90 \%$ humidity for a period between 1.5 and 2 times the workability period of the mixture (if lime and cement are used) or $72 \pm 2 \mathrm{~h}$ for lime only. The specimens are then prepared for immersion by confining them with a fabric cover held in place with elastic bracelets, then fully immersed for $168 \pm 4 \mathrm{~h}$ in water at $40 \pm 2{ }^{\circ} \mathrm{C}$. After this time the specimens are measured and the percentage volumetric expansion $\left(G_{v}\right)$ is calculated.

The specimens and curing chamber are shown in Figure 1. The humidity in the climatic chamber used to cure the specimens is maintained at greater than $90 \%$ by a saturated solution of potassium chloride at the bottom of the chamber.
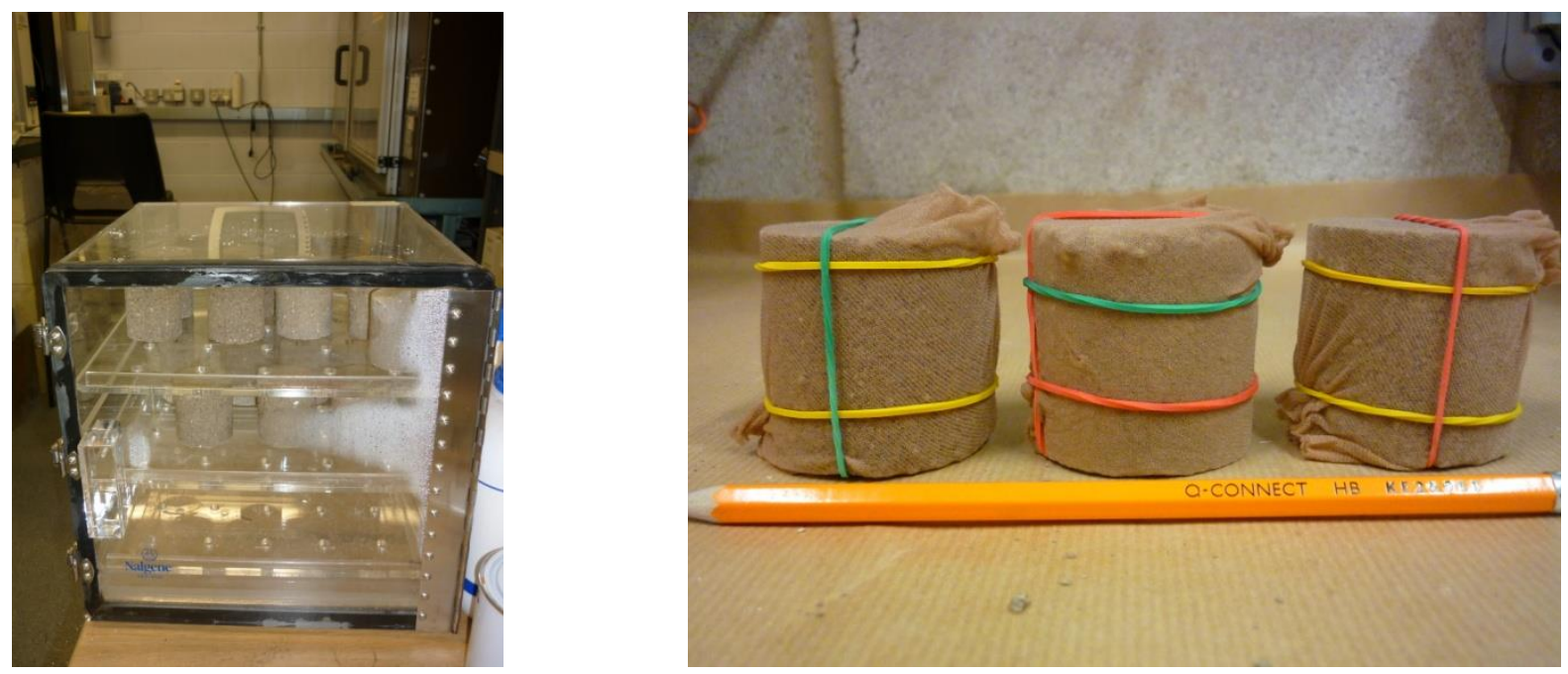

Figure 1: Climatic air curing chamber and wrapped specimens prior to immersion (EN 13286-49)

Digital callipers are used to measure the dimensions of the specimen periodically during the immersion period. The volume of the specimen is calculated from the average height (determined from two measurements) and the average diameter (three measurements).

The initial volume $\left(V_{0}\right)$ after demoulding is measured prior to immersion. The volume after immersion $\left(V_{1}\right)$ is measured at the end of the soaking period. The volume of the specimen and the confinement wrapping is $V_{2}$. Volumetric expansion (Gv) is given by (8):

$$
G_{v}(\%)=100 \times \frac{\left[\left(V_{1}-V_{2}\right)\right]}{V_{0}}
$$

where: $V_{0}$ is the initial volume, $V_{1}$ is the volume after immersion, $V_{2}$ is the volume of the confinement wrapping

The European accelerated swelling test is unconfined and allows expansion in all directions. The pass/fail criteria for this test is given in the European standard EN 14227-11 (2006) 'Hydraulically bound mixtures, Specifications - Part 11: Soil treated by lime' [18]. It defines that if the volumetric swell $\left(G_{v}\right)$ at the end of the test is greater than $5 \%$ then the soil is not suitable for stabilisation. However it does note that 'where the volumetric swelling is greater than $5 \%$ but does not exceed 
$10 \%$, the use of the mixture is generally not possible; however a complementary study can be made according to experience at the place of use.'

\section{Compositional and Microstructural Analysis}

Samples were taken from the side of the European accelerated swell test specimens using a palette knife for compositional analysis. This consisted of: X-ray Diffraction (XRD); derivative Thermogravimetric Analysis (dTGA) and Scanning Electron Microscope (SEM) and X-ray Computer Tomography (X-ray CT). This material was crumbled into glass dishes. These were then freeze-dried by first freezing at $-80^{\circ} \mathrm{C}$ overnight, then vacuum dried. This procedure halted the hydration reactions thus preserving the phase assemblage and what original micro-structure remained (petrographic analysis is difficult to perform on low strength materials due to the cutting and polishing required to produce a surface suitable for analysis). Samples for Scanning Electron Microscope (SEM) were reserved as is. Those for XRD and TGA were gently ground with a mortar and pestle then passed through a $425 \mu \mathrm{m}$ sieve to yield a homogenous powder.

For XRD analysis, the prepared soil powders were analysed on standard $27 \mathrm{~mm}$ sample holders using a Siemens D500 diffractometer using CuKa radiation at an accelerating voltage of $40 \mathrm{kV}$ and 25 $\mathrm{mA}$ current. The samples were analysed between $8-10.5^{\circ} 2 \theta$, using a $0.02^{\circ}$ step, and a count time of 60 s/step.

For TGA analysis, the soil samples used in the XRD analysis were also subject to TGA under nitrogen at $20 \mathrm{ml} / \mathrm{min}$, using the following programme on a Perkin Elmer Pyris 1 TGA:

- Hold for $10 \mathrm{~min}$ at $30^{\circ} \mathrm{C}$

- Heat from $30^{\circ} \mathrm{C}$ to $180^{\circ} \mathrm{C}$ at $2^{\circ} / \mathrm{min}$;

- Hold for $5 \mathrm{~min}$ at $180^{\circ} \mathrm{C}$; and

- Heat from $180^{\circ} \mathrm{C}$ to $900^{\circ} \mathrm{C}$ at $10^{\circ} / \mathrm{min}$.

Soil samples were analysed using a Philips FEI XL30 Scanning Electron Microscope (SEM) to investigate the morphology of the crystalline phases and as far as possible the microstructure. After freeze-drying, specimens were mounted on SEM stubs using carbon discs. The samples were then coated with Platinum using a Polaron SC7640 sputter coater. Analysis was undertaken in high vacuum at a pressure of about $3.5 \times 10^{-6} \mathrm{mbar}$, using an accelerating voltage of $5-20 \mathrm{kV}$, working distance of $10-20 \mathrm{~mm}$, and a spot size of $2-5$ (arbitrary units). The image was composed from detection of secondary electron emissions.

Energy Dispersive X-ray (EDX) spectroscopy was undertaken to determine the elemental composition using point analysis. This was achieved using an accelerating voltage of $15 \mathrm{kV}$, a working distance of $15 \mathrm{~mm}$ and a spot size of approximately 5 (arbitrary units). The INCA EDX software programme was used for data and image processing. 
X-Ray Computer Tomography (X-Ray CT) is an imaging technique that allows a three-dimensional image to be compiled from two-dimensional X-Ray images taken around a single axis of rotation. It is used here along with the image processing software ImageJ to characterise the void structure of swell test specimens produced in accordance with the two swell test procedures. A XTEC X-ray CT analyser was used in the analysis. All images were acquired using the mini-focus $350 \mathrm{kV} \mathrm{X}$-ray source system and linear detector. The images were processed using the software IMPS III. X-Ray CT analysis was only undertaken at the end of the curing period (EAK3 and EAM3) and after 14 days immersion (EAK8 and EAM8) in accordance with the test regime described in the next section.

\section{Test Regime}

The schedule by which the specimens are measured and analysed is given in Table 3. A set of three specimens are used for the measurement of volumetric swell. In order to better resolve the evolution of the volumetric swell, this was measured at additional points at $48 \mathrm{~h}, 4,59$ and 11 days after immersion The remaining five specimens are then removed periodically from the test and freeze dried to arrest any further chemical changes. They were then subject to the spectroscopic and chemical analysis. The specified immersion period in the test standard (EN13286-49) is seven days. This was increased to 14 days to determine the effects of extended immersion on the physicochemical properties.

Table 3: Test regime for early age study

\begin{tabular}{|c|c|c|}
\hline \multirow{2}{*}{ Event } & \multicolumn{2}{|c|}{ Specimen ID } \\
\cline { 2 - 3 } & K4L5S & M6L5S \\
\hline Soil mixing $+1 \mathrm{~h}$ & EAK1 & EAM1 \\
\hline Soil mixing $+24 \mathrm{~h}$ & EAK2 & EAM2 \\
\hline End Curing $(72 \mathrm{~h})$ & EAK3 & EAM3 \\
\hline Immersion $+1 \mathrm{~h}$ & EAK4 & EAM4 \\
\hline Immersion $+24 \mathrm{~h}(1$ day $)$ & EAK5 & EAM5 \\
\hline Immersion $+72 \mathrm{~h}(3$ days $)$ & EAK6 & EAM6 \\
\hline Immersion $+168 \mathrm{~h}(7$ days $)$ & EAK7 & EAM7 \\
\hline Immersion $+336 \mathrm{~h}$ (14 days $)$ & EAK8 & EAM8 \\
\hline
\end{tabular}

Results

\section{Volumetric Swell Testing}

The results of the volumetric swell testing in addition to the change in $\mathrm{pH}$ are shown in Figure 2. 


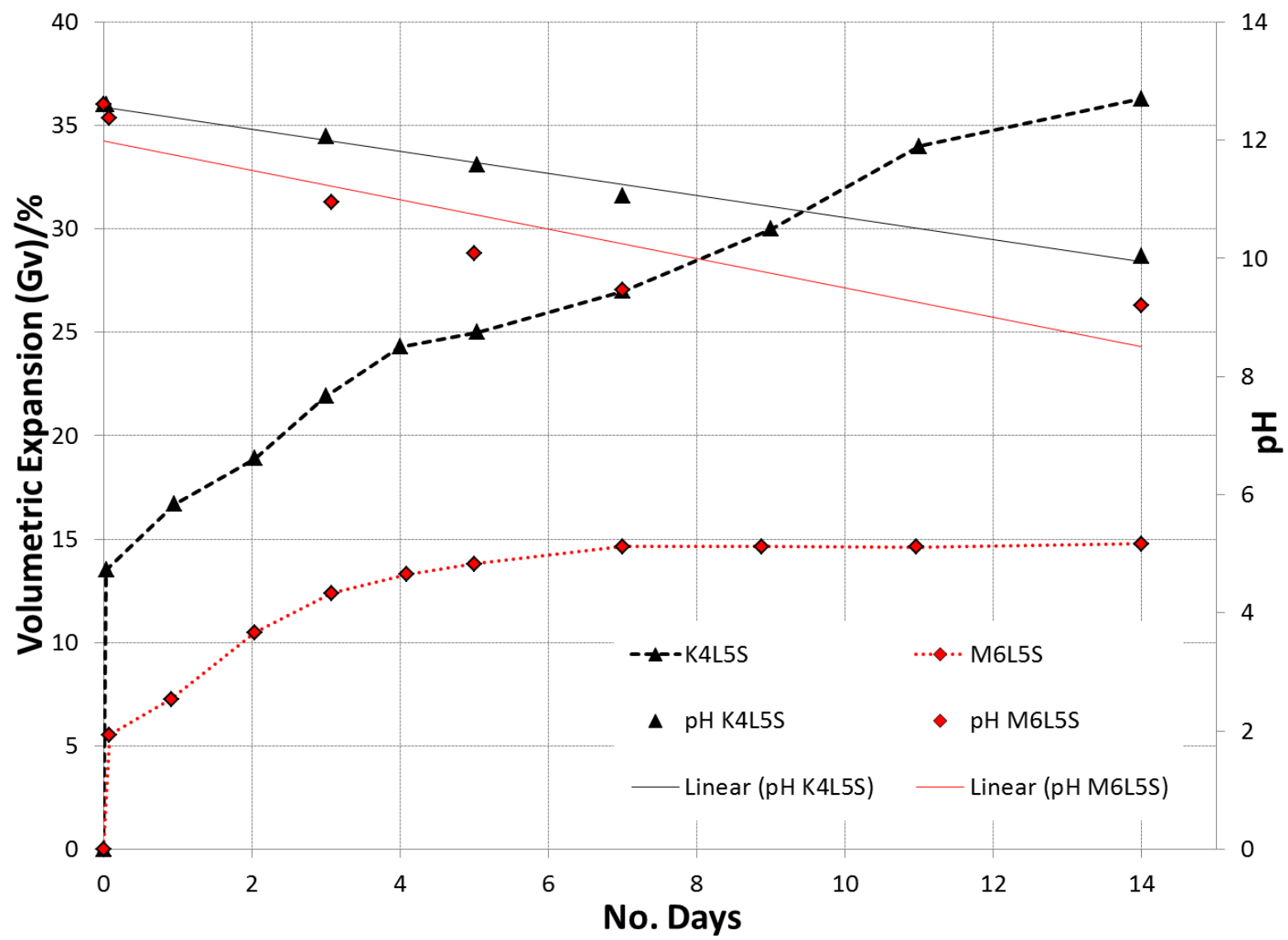

Figure 2: volumetric swell testing results (EN 13286-49)

The kaolin soil (K4L5S) swelled initially (at immersion +1 hour) to $13.5 \%$, after which it followed a roughly linear upward trend, achieving a total swell after 14 days immersion of $36.3 \%$. A relatively rapid initial expansion, on immersion +1 hour (EAM4) was observed (Gv 5.0\%), after which the volumetric swell exhibited a more linear increase until ca. four days immersion upon which the swell began to plateau. The total volumetric swell observed was $15.6 \%$

Visual assessment of the kaolin based soils showed that the specimens EAK7 to EAK8 exhibited severe volumetric disruption in all directions, with the soil itself losing a large degree of its cohesiveness. The montmorillonite on the other hand, while it still exhibited volumetric expansion (not as much as the kaolin), retained more of its original shape. A smaller loss of cohesiveness was also observed, but only at the specimen edges.

The $\mathrm{pH}$ value and water content of each specimen was determined (Table 4). In the kaolin soils, the $\mathrm{pH}$ remained above $\mathrm{pH}$ 12.4, where pozzolanic reactions are possible (Little, 1999) until the specimens reached the end of their curing period (EAK4). 24 hours immersion caused a drop in soil $\mathrm{pH}$ to 12.06 and decreased further thereafter finally reaching a value of $\mathrm{pH} 10.04$ after 14 days immersion. The water content of the soils remained consistent prior to immersion (as would be expected since external water has not been introduced to the system yet), then increased with the duration of immersion. The montmorillonite soil on mixing, reaches a $\mathrm{pH}$ of 12.61 . As the soil ages 
and the test progresses, the $\mathrm{pH}$ drops to a value of $\mathrm{pH}$ 9.38. As is typically associated with sulfate induced volumetric swell, the water content of the specimens also increases

Table 4: $\mathrm{pH}$ and water content values of the early age specimens

\begin{tabular}{|c|c|c|c|c|c|c|c|c|c|}
\hline & $\begin{array}{c}\text { Sample } \\
\text { ID }\end{array}$ & \multicolumn{1}{|c|}{$\begin{array}{c}1 \\
\mathrm{~m}+1 \mathrm{~h}\end{array}$} & $\mathrm{~m}+24 \mathrm{~h}$ & $\mathrm{end}$ cure & $\mathrm{i}+1 \mathrm{~h}$ & $\mathrm{i}+1 \mathrm{~d}$ & $\mathrm{i}+3 \mathrm{~d}$ & $\mathrm{i}+7 \mathrm{~d}$ & $\mathrm{i}+14 \mathrm{~d}$ \\
\hline \multirow{2}{*}{$\mathbf{p H}$} & $\mathrm{EAK}+$ & 12.65 & 12.68 & 12.60 & 12.60 & 12.06 & 11.58 & 11.17 & 10.04 \\
\cline { 2 - 12 } & EAM+ & 12.61 & 12.57 & 12.45 & 12.38 & 10.95 & 10.08 & 9.47 & 9.38 \\
\hline \multirow{2}{*}{ WC (\%) } & EAK+ & 23.1 & 23.2 & 23.1 & 31.7 & 49.1 & 53.4 & 54.8 & 62.3 \\
\cline { 2 - 12 } & EAM+ & 20.61 & 20.5 & 20.6 & 26.6 & 33.1 & 38.5 & 40.1 & 49.6 \\
\hline
\end{tabular}

.Note: $\mathrm{m}$ - mixing, $\mathrm{h}$ - hour, $\mathrm{i}$ - immersion, $\mathrm{d}$ - day.

\section{Microstructural Analysis by X-Ray CT}

Microstructural analysis was undertaken on EAM3 (post cure) and EAM8 (14 days immersion). Unfortunately, it was not possible to run the equivalent kaolins, because after immersion, sample EAK8 had lost such a degree of cohesiveness that it fell apart on handling. Therefore, only the montmorillonite based samples were used. These were subject to X-ray Computed Tomography (Xray $\mathrm{CT}$ ) using a XTEC X-ray CT analyser. All images were acquired using the mini-focus $350 \mathrm{kV} \mathrm{X}$-ray source system and linear detector. The images were processed using the software IMPS III. The specimens were scanned at $0.5 \mathrm{~mm}$ intervals to achieve a set of 2-dimensional 'slices' through each specimen. These were then processed using the open source image analysis software ImageJ (Abràmoff et al, 2004) with the additional plugin 3D viewer [19].

$3 \mathrm{D}$ renderings of the internal structure were produced by first cropping the raw image and processing it through the filter Gaussian Blur, before adjusting the threshold so that the voids are fully incorporated. This had to be done manually because the brightness of the set of images was not consistent. Setting the appropriate greyscale threshold limit then produced a binary (black and white) image of each slice with the voiding coloured black, the sequence of which is shown in Figure 3. 


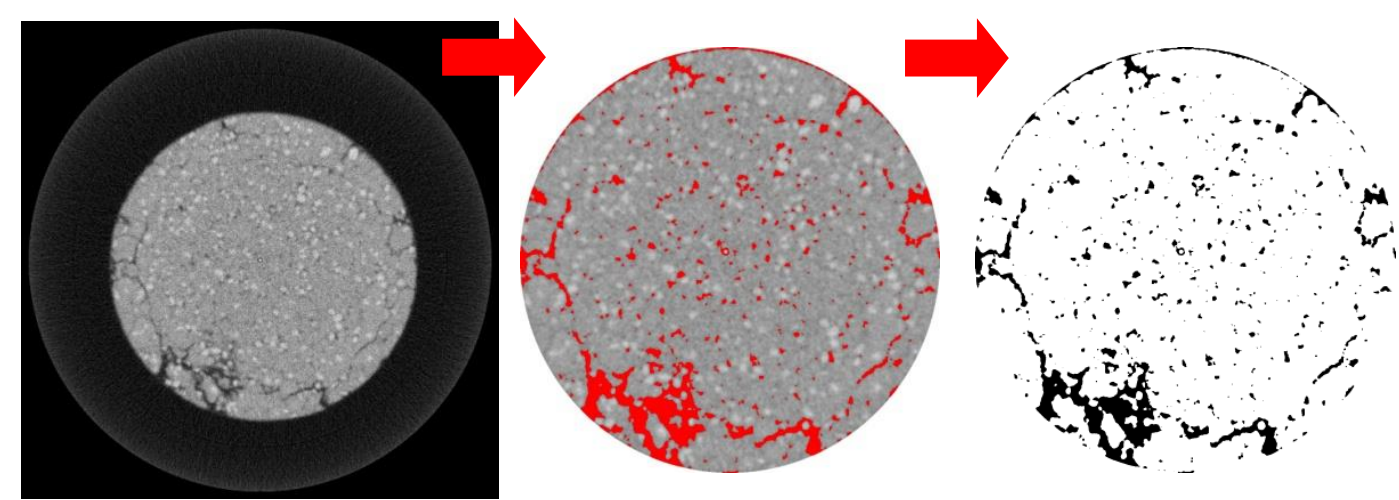

Figure 3: Creation of a binary image from an X-Ray CT 'slice'

These were then combined using the 'stack' function and projected along the z-axis by equating the pixel distance of the images to the correct length (in this case $0.5 \mathrm{~mm}$ ). They were then 'resliced' so that the 2D stack of the void structure was rendered in $3 \mathrm{D}$ by associating the void on one slice to its two neighbours above and below, creating a voxel (3D pixel). The transparency was then adjusted so that a reasonable image of the microstructure was achieved. The initial microstructural state of the EAM3 (post cure) is shown in Figure 4.
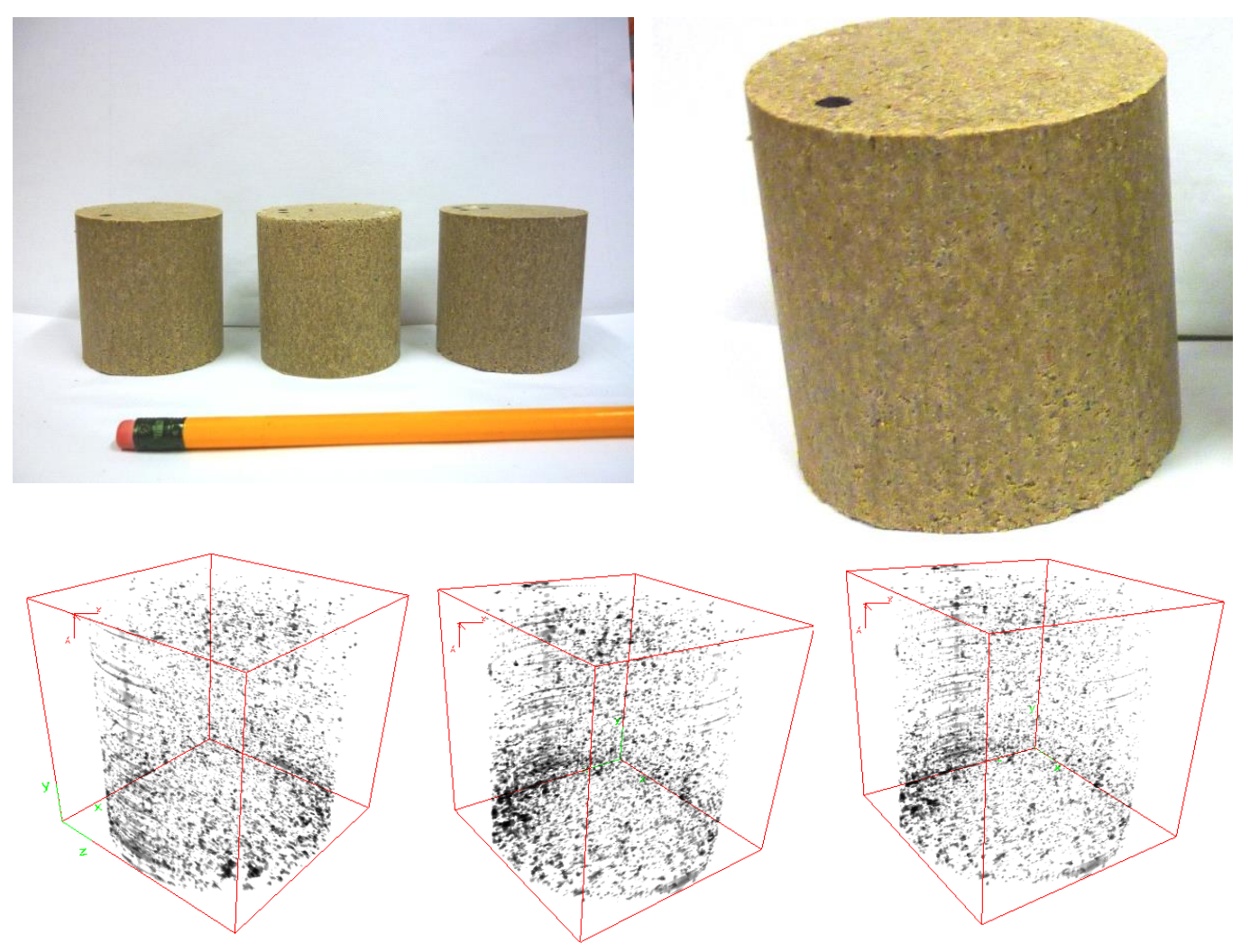

Figure 4: Pre-immersion (EN13286-49) of the early age montmorillonite specimens. Lower images show the 3D construction of the initial void structure derived from X-ray CT scans (100 slices at 0.5 $\mathrm{mm}$ intervals) 
As can be seen from Figure 4, the starting microstructure is still relatively porous. The voiding is not uniform throughout the specimen, with a higher concentration of void spaces near the bottom of the specimen. This is due to the static compaction used in their manufacture. The force used to extrude the specimens was applied from the top, so resulted in a degree of additional compaction at this end.

Figure 5 shows the effect of 14 days immersion on the microstructure of the montmorillonite soils (EAM8). The volumetric expansion of the soil was evident from the increased number of X-ray CT slices required to fully image the specimen (106 post-immersion vs 100 pre-immersion) which equated to a linear increase along the z-axis of $3 \mathrm{~mm}$. An increase in the lateral $x, y$-axes were also observed. The post cure specimen had a 2D image size of $1220 \times 1220$ pixels, whereas the post immersion specimen had a 2D image size of $1300 \times 1300$. This equated to an increase in radius of the specimen analysed of $3.3 \mathrm{~mm}$. Based on these measurements, the specimen did not exhibit expansion in a preferred direction, but expanded uniformly over its $\mathrm{x}, \mathrm{y}$,and $\mathrm{z}$-axes.

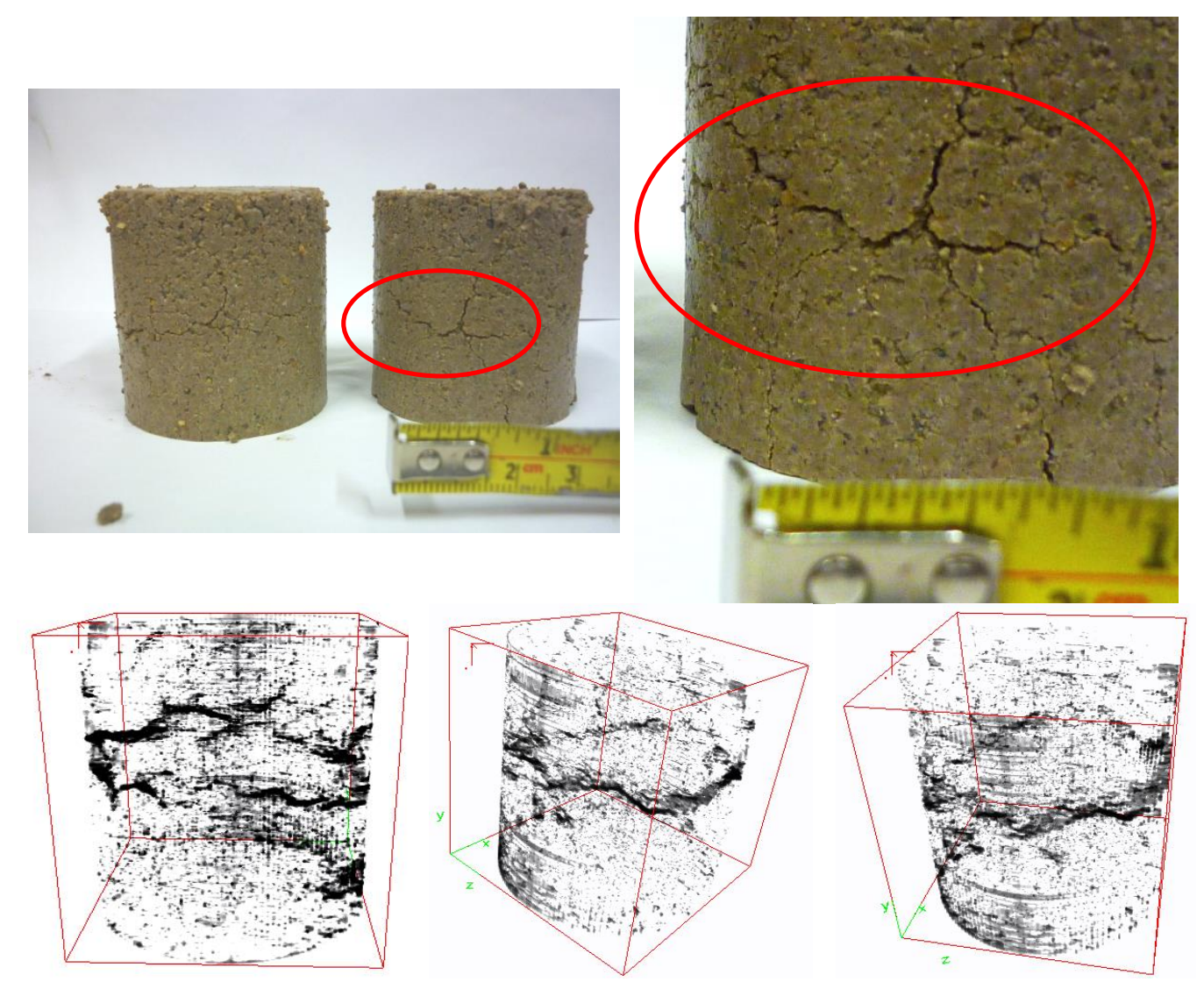

Figure 5: Post-immersion after 14 days (EN13286-49) of the montmorillonite specimens. Lower images show the 3D construction of X-ray CT scans of M6L5S after 14 days immersion showing damage to specimen microstructure

(106 slices at $0.5 \mathrm{~mm}$ intervals)

As well as the observed expansion, the specimen also exhibited deterioration manifested as fractures around its circumference (circled in Figure 5). These appeared to start from the outside of the 
specimen in contact with the water and radiate inwards and are probably a function of the specimens' permeability.

\subsection{X-RAY DIFFRACTION}

The scans were undertaken on a Brucker D500 using CuKa radiation over the range $8-10.5^{\circ} 2 \theta$, step size $0.02^{\circ}$ and 60 s count time.

The low angle XRD patterns of the kaolin soils (EAK1 - EAK8) are shown in Figure 6. The illite peak (Powder Diffraction File, PDF. 01-072-0646) at $8.85^{\circ} 2 \theta$ is present in all the soils, and is of roughly the same intensity. The [100] AFt peak (PDF. 01-072-0646) at ca. $9.15^{\circ} 2 \theta$ is present at relatively early ages in the kaolin, and appears to reach a maximum in EAK7 (after 7 days immersion) then decreases in EAK8 (14 days immersion). The peak position of AFt does not change significantly over the duration of the test, indicating its morphology is consistent. Changes in peak position have been attributed to compositional and morphological changes in the AFt crystal [20] [21] [22]. 
Illite [001], $8.842 \theta$
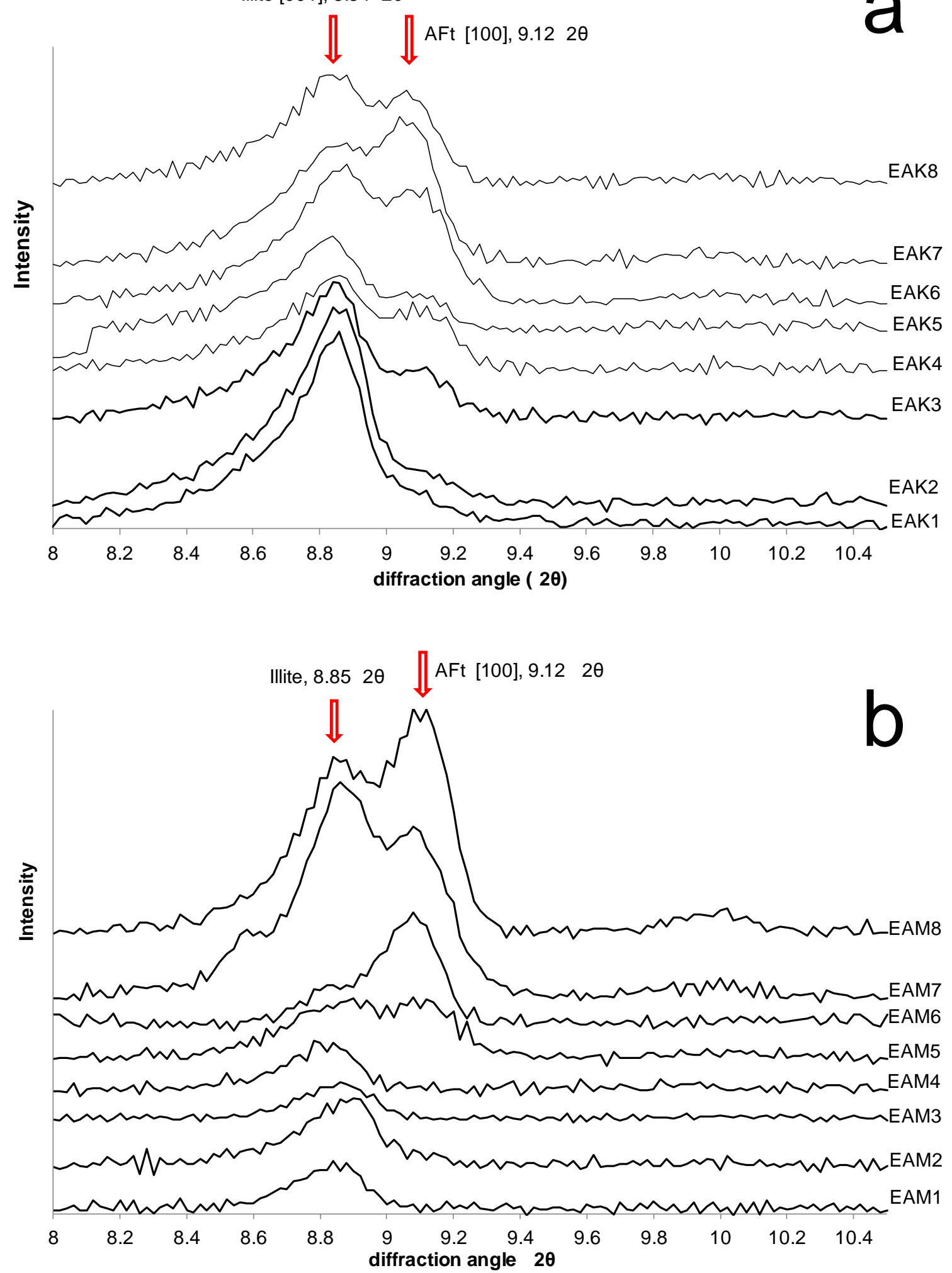

Figure 6: Low angle XRD pattern of kaolin soils (a) and the equivalent montmorillonite soils (b) showing the reflection peak of illite and the development of the [100] AFt peak as the test progresses 
In the kaolin soils both the position and intensity of the illite peak does not change significantly throughout the series. The variability in the maximum peak intensity $\left(I_{\max }\right)$ of the AFt peak is quite large, although the $I_{\max }$ of the last three soils (EAK6-8) is larger than the earlier five (EAK1-5).

The considering the low angle XRD patterns of the montmorillonite soils (EAM1 - EAM8), the intensity of the illite peak at $8.85^{\circ} 2 \theta$ is again fairly consistent over soils EAM1 to EAM6, but increases in intensity at 7 and 14 days immersion (EAM7 and EAM8). The AFt peak at $9.15^{\circ} 2 \theta$ again does not shift position over the duration of the test and, in contrast to the kaolin soils, is not detectable until EAM5 (immersion $+24 \mathrm{~h}$ ), after which it increases in intensity in the order EAM5<EAM6<EAM7<EAM8.

The montmorillonite soils exhibit quite a markedly different behaviour over the series. The intensity of both the illite and AFt peaks increases as the immersion test progresses, although ettringite was not detectable until EAM5 by which time the specimens had been immersed in the water bath for 24 hours.

Derivative Thermalgravimetric Analysis (dTGA)

The dDTA plots of K4L5S EAK1- EAK8 are shown in Figure 7. The main features are: $c a \cdot 55^{\circ} \mathrm{C}-$ desorption of clay surface water (1); ca. $425^{\circ} \mathrm{C}$ - dehydration of $\mathrm{Ca}(\mathrm{OH})_{2}(3)$; and ca. $90{ }^{\circ} \mathrm{C}-$ ettringite (6).

After the soil has been initially mixed (EAK1), the peak attributed to $\mathrm{Ca}(\mathrm{OH})_{2}$, (3) generally reduces in intensity and is not observed at all in EAK7 and EAK8. It was found however, that the $\mathrm{Ca}(\mathrm{OH})_{2}$ peak was bigger in EAK5 (immersion $+1 \mathrm{~h}$ ) than EAK4 (immersion $+24 \mathrm{~h}$ ). This may be due to the effect of a small sample size combined with a degree of inhomogeneity within the bulk sample itself. Overall, the peak corresponding to the desorption of surface water from the clay (1) increases with the amount of time the specimens are immersed. The AFt peak at ca. $80^{\circ} \mathrm{C}(6)$ is broadly of the same intensity over all the samples, again with the exception of EAK4, which is much higher. 

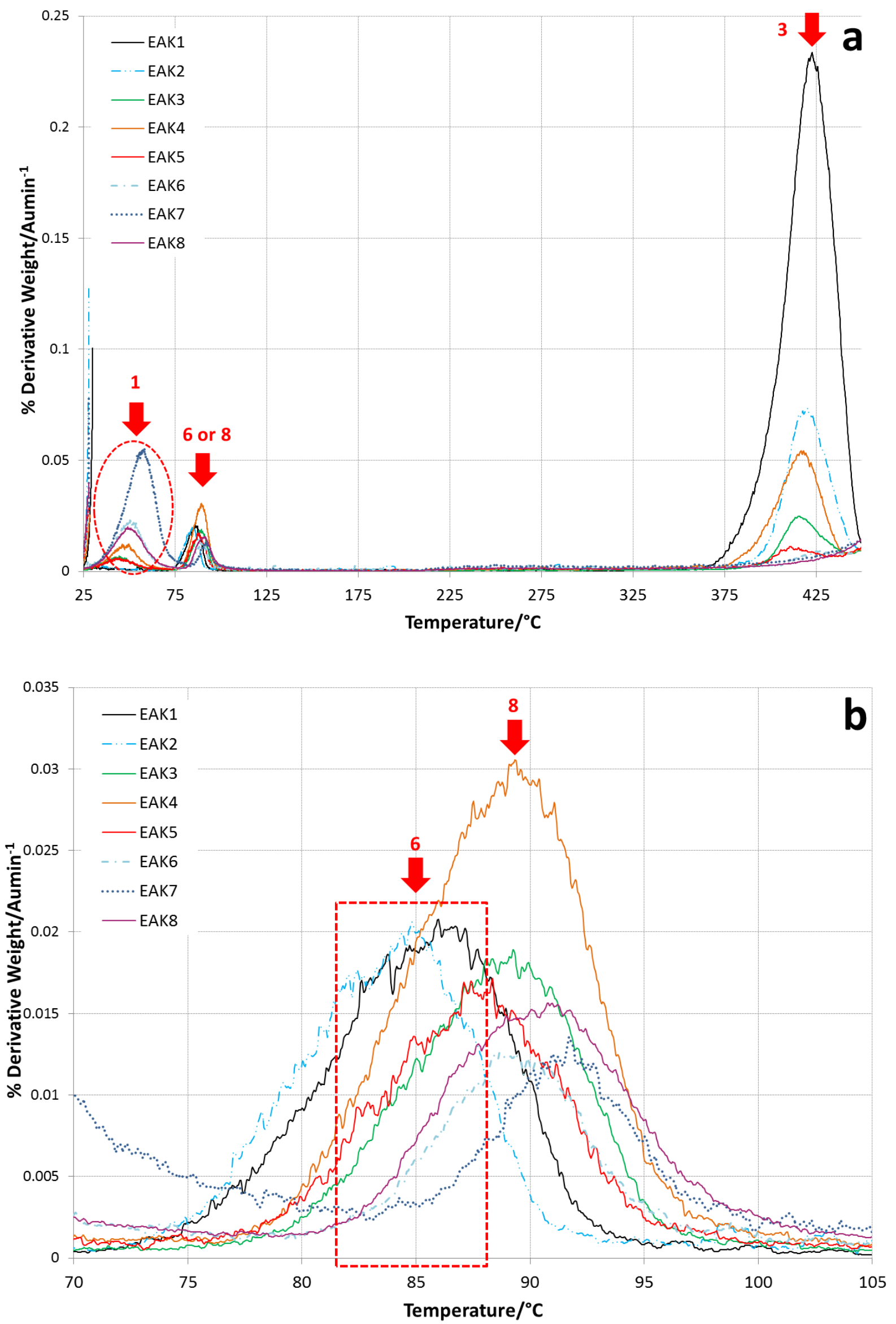
Figure 7: dTGA analysis of K4L5S early age study specimens (EAK1-8). 1 - desorption $\mathrm{H}_{2} \mathrm{O}, 3$ $\mathrm{Ca}(\mathrm{OH})_{2}, 6$ - ettringite (AFt). (a) primarily shows dehydration of the parent clay and hydrated lime. (b) shows in greater detail the area at which both gypsum and ettringite dehydration is likely to occur.

Table 5 shows the position (in terms of temperature) of the peak at the maximum rate of weight loss around $90^{\circ} \mathrm{C}$. The purpose of this was to try and differentiate peaks that may be either gypsum or ettringite.

Table 5: Temperature at $\Delta \mathrm{Y}_{(\max )}$ for peak at ca. $90^{\circ} \mathrm{C}$

\begin{tabular}{|c|c|c|c|c|c|c|c|c|c|}
\hline & & \multicolumn{8}{|c|}{ Temperature at $\Delta \mathrm{Y}_{(\max )}\left({ }^{\circ} \mathrm{C}\right)$ at $90^{\circ} \mathrm{C}$} \\
\hline \multirow{3}{*}{ Specimen ID } & \multirow{3}{*}{ EAK+ } & 1 & 2 & & 4 & 5 & 6 & 7 & 8 \\
\hline & & $m+1 h$ & $m+24 h$ & cure & $\mathbf{i}+\mathbf{1 h}$ & $\mathrm{i}+\mathbf{1 d}$ & $i+3 d$ & $\mathrm{i}+7 \mathrm{~d}$ & $i+14 d$ \\
\hline & & 84.0 & 85.3 & 88.4 & 90.0 & 87.2 & 88.9 & 91.2 & 90.5 \\
\hline
\end{tabular}

Note: $\mathrm{m}$ - mixing, $\mathrm{h}$ - hour, $\mathrm{i}$ - immersion, $\mathrm{d}$ - day.

From the XRD and SEM studies, no ettringite was detected in EAK1 or EAK2. The max temperature at $\Delta \mathrm{Y}_{(\max )}$ was about $85^{\circ} \mathrm{C}$, this then shifted up to about $90^{\circ} \mathrm{C}$ in EAK3 to EAK8. This could be evidence of two distinct phases in these samples, namely the existing gypsum and the formation of ettringite. It may be possible however, that encapsulation of gypsum within the cementing clay also shifts the temperature upwards.

The dTGA analysis of the montmorillonite soils (M6L5S, EAM1-8) is shown in Figure 8. (a) shows the dTGA response in the range from $25-500^{\circ} \mathrm{C}$ and (b) shows the area circled in more detail. 

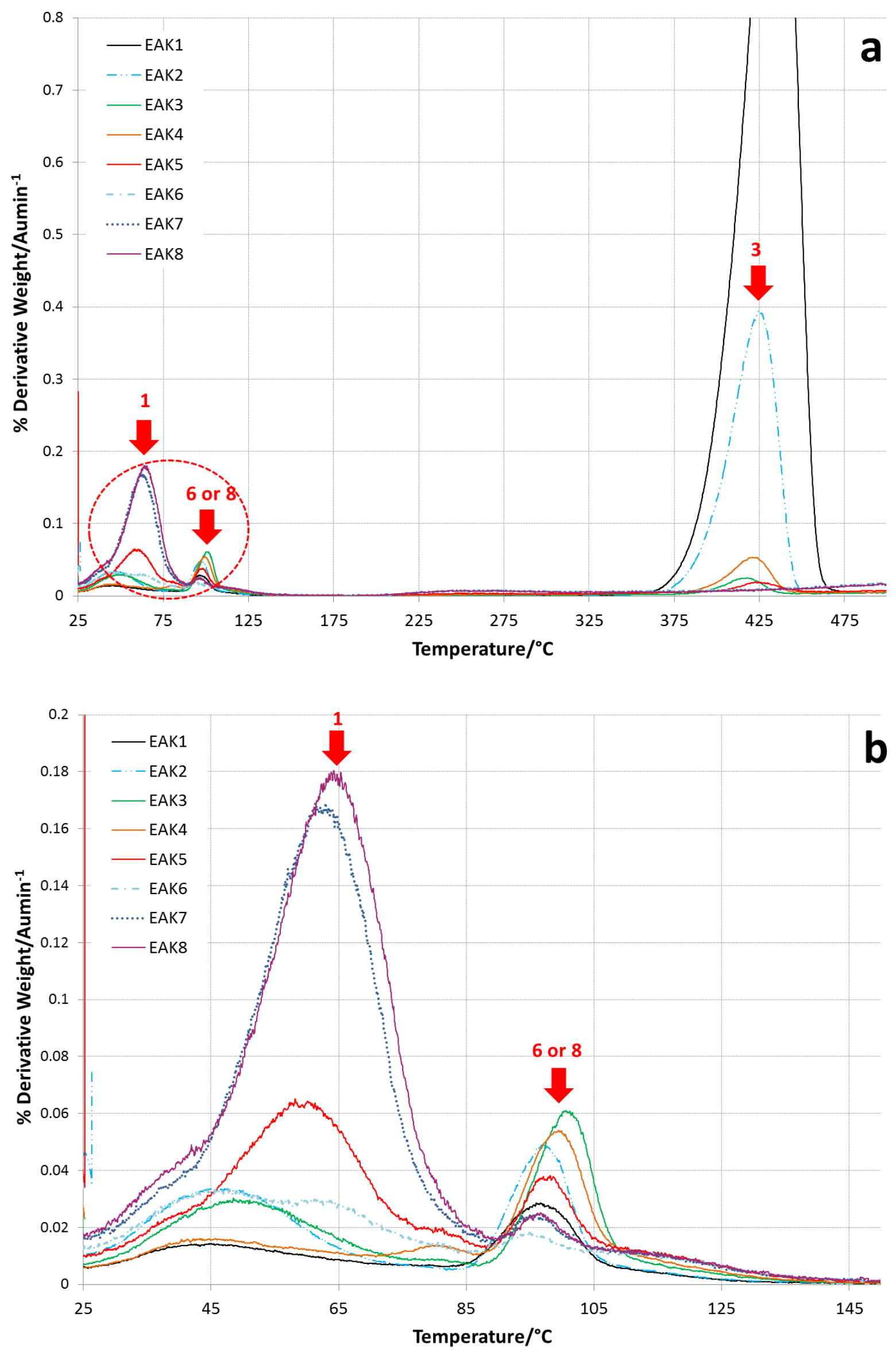
Figure 8: dTGA analysis of M6L5S early age study specimens (EAM1-8). 1 - desorption $\mathrm{H}_{2} \mathrm{O}, 3$ $\mathrm{Ca}(\mathrm{OH})_{2}, 6$ - ettringite $(\mathrm{AFt}), 8-\mathrm{CaSO}_{4} \cdot 2 \mathrm{H}_{2} \mathrm{O}$. (a) primarily shows dehydration of the parent clay and hydrated lime. (b) shows in greater detail the area at which both gypsum and ettringite dehydration is likely to occur.

The following peaks were identified: peak at ca. $40-60^{\circ} \mathrm{C}$ attributed to loss of adsorbed water from the clay (1); dehydration of $\mathrm{Ca}(\mathrm{OH})_{2}$ at ca. $425^{\circ} \mathrm{C}$ (3); ca. $80-100^{\circ} \mathrm{C}$ ettringite (6) and ca. $92-105^{\circ} \mathrm{C}$ ettringite or gypsum (6 or 8 ). Over the course of the immersion period, the reduction in peak (3) attributed to lime is quite significant. This represents the consumption of lime through pozzolanic reactions (including deleterious mineral formation) as well as on-going cation exchange processes. Increasing the duration of immersion (EAM4 to EAM8) results in a larger adsorbed water peak from the clay (1) compared to EAM3 (end cure). This effect is most significant for EAM7 and EAM8 (7 and 14 days immersion).

Table 6 shows the calculated amounts of residual hydrated lime $\left(\mathrm{Ca}(\mathrm{OH})_{2}\right)$ based on the peak area of the thermal dehydration event of $\mathrm{Ca}(\mathrm{OH})_{2}$ at ca. $425^{\circ} \mathrm{C}$. The calculation assumes that all of the added calcium oxide $(\mathrm{CaO})$ has been converted to $\mathrm{Ca}(\mathrm{OH})_{2}$. But the data serves to illustrate the degree of reaction within each soil system.

Table 6: Residual $\mathrm{Ca}(\mathrm{OH})_{2}$ content calculated from dTGA analysis for EAK and EAM 1 - 8 specimens

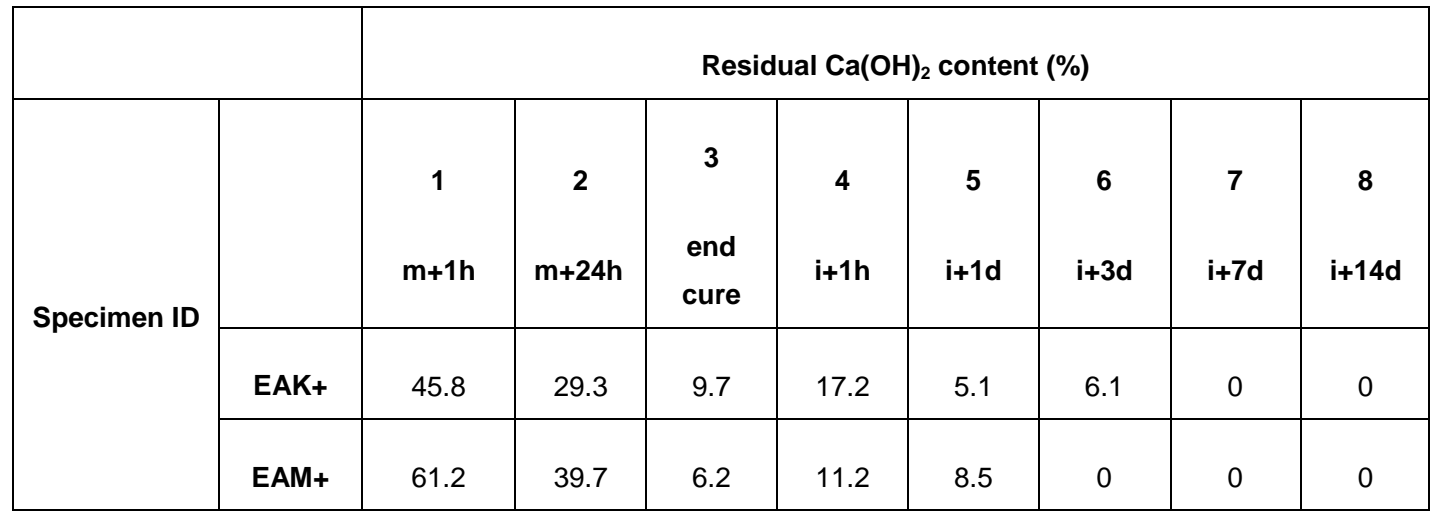

Note: $\mathrm{m}$ - mixing, $\mathrm{h}$ - hour, $\mathrm{i}$ - immersion, $\mathrm{d}$ - day.

The results in Table 6 show that $\mathrm{Ca}(\mathrm{OH})_{2}$ persisted for a longer time in the kaolin soils, since it was still detectable in EAK6 (immersion+3 days). Despite higher detectable levels in the montmorillonite soil (61.2\% in EAM1) the residual content dropped off rapidly by the end of the curing period (EAM3), which serves to illustrate the high cation exchange capacity (CEC) of 2:1 layer clay. Lime could not be detected at all from EAM6 onwards. The slight increase in both soils at EAK4 and EAM4 is caused by the immersion of the specimens in the water, resulting in saturation of the sample (and any unreacted $\mathrm{CaO})$. 


\section{SEM-EDX ANALYSIS}

High Sulfate Kaolin Soil (K4L5S)

Figure 9 (a) shows representative SEM-EDX analysis of EAK1 (mixing $+1 \mathrm{~h}$ ). The soil remains unchanged with little evidence of either ettringite formation or any cementitious products. The EDX of the clay (EDX7a) reveals typical elemental emissions of the parent clay. Note the low emission of $\mathrm{Ca}$. This could be viewed as an indication of a low degree of cationic substitution (CEC processes) at this stage. EAK2 (Figure 9, b) also showed that the clay remained largely unchanged. The SEM-EDX analysis of EAK3 (end of cure) is shown in Figure 9 (c). The micrographs show what seems to remain of a void structure. On the wall of this structure is an area of crystal growth that may be the early formation of AFt. EDX7c shows the area to be relatively rich in $\mathrm{Ca}$, along with $\mathrm{Al}, \mathrm{Si}$ and $\mathrm{S}$ and is indicative of a primitive ettringite crystal structure. Figure 9 (d) shows a similar structure found in EAK4 (immersion $+1 \mathrm{~h}$ ). EDX7d shows a predominantly clay material with an elemental composition comprising mainly of $\mathrm{Al}, \mathrm{Si}$ and $\mathrm{O}$ with smaller amounts of $\mathrm{Ca}$. EDX7e shows an early ettringite nucleation point with crystals having a very similar elemental composition to that found in EDX7c, Figure 9 (c). This Ca-rich primitive ettringite was recently reported by Tosun and Baradan [23] in their studies of Delayed Ettringite Formation (DEF) of cement based mortars and described as 'ball ettringite'. 

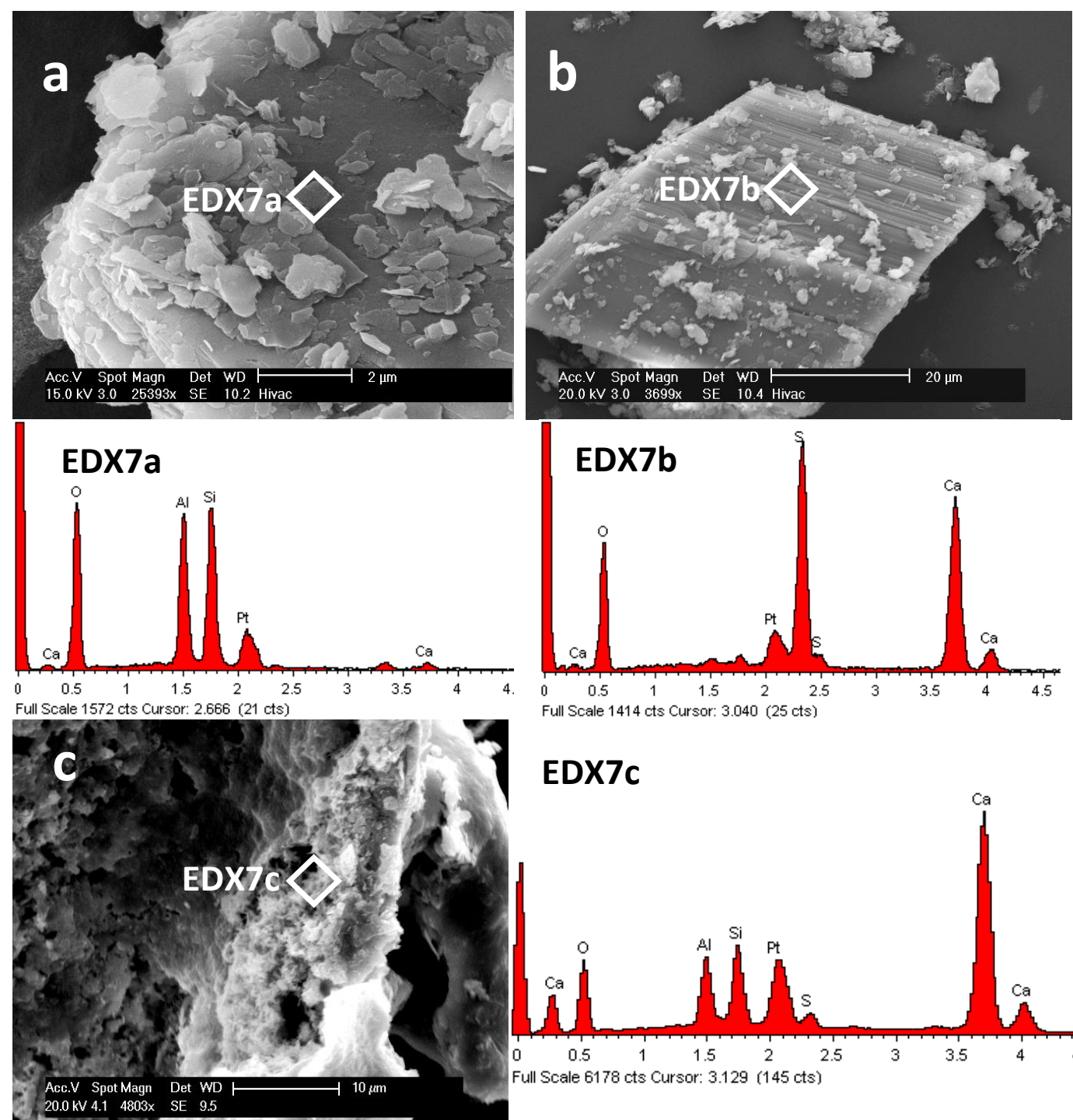

\section{EDX7c}
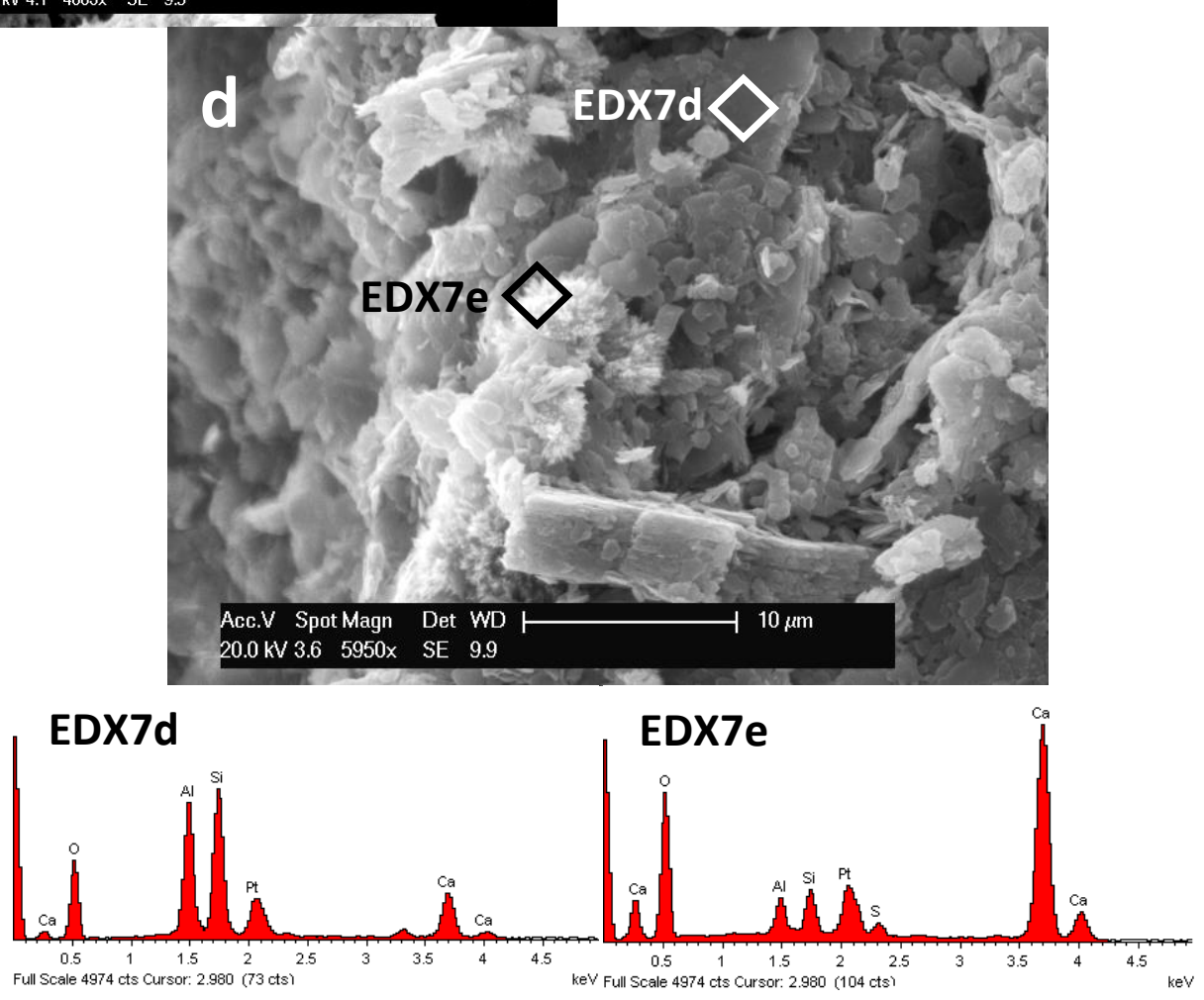
Figure 9: SEM-EDX of EAK1 showing typical plate-like morphology of the kaolin clay (a) and unreacted gypsum particle (b), and early age ettringite in EAK3 (c) and EAK4 (d)

Figure 10 shows an interesting feature found in EAK5 (immersion $+24 \mathrm{~h}$ ). The top left micrograph shows regions of crystal growth over the surface of the clay material, that appear to be intersecting with each other. They are comprised of acicular crystals growing along the same axis. The area circled is shown at greater magnification in the top right micrograph. EDX point analysis has been taken from both and shown in EDX7f and EDX7g. The intersecting crystal growth (c) has an EDX emission spectrum similar to that of the ettringite crystals found in the specimen tested after immersion +1 hour (EAK4, Figure 11). The structure circled however, is predominantly rich in Ca and reduced emissions (comparatively) from $\mathrm{Al}, \mathrm{Si}$ and $\mathrm{O}$. The $\mathrm{S}$ peak is roughly similar to that shown in EDX7f. 

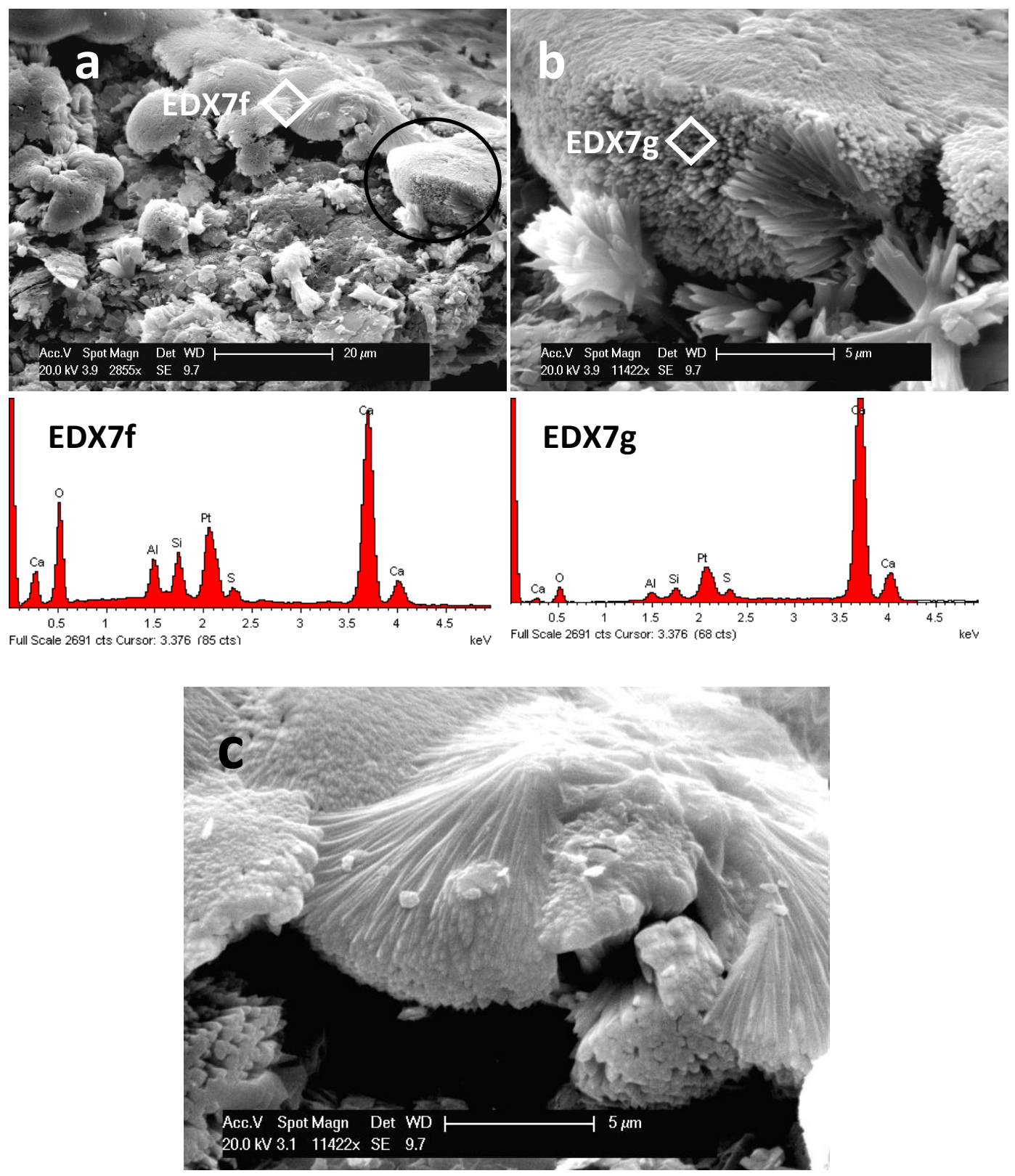

Figure 10: EAK5 showing intersecting regions of acicular crystal growth (a), (b) and at higher magnification (c)

Figure $11 \mathrm{a}-\mathrm{c}$ show a series of micrographs taken of EAK6 (immersion +3 days) to EAK8 (immersion + 14 days). Ettringite was found in all of the test samples. In EAK6 through to EAK7, the AFt crystals are of relatively similar size (ca. $7 \mu \mathrm{m} \times 0.7 \mu \mathrm{m}$ ). In the right micrograph of EAK6 (circled) fine AFt, which could possibly be described as colloidal in nature is present. The SEM micrograph of EAK8 (immersion +14 days) reveals the presence of significantly larger AFt crystals, indicating the presence of two distinct crystal morphologies. The formation of two distinct AFt crystal morphologies is shown again Figure 11 (d). The accompanying EDX analysis (EDX7h and EDX7i) reveal both to be ettringite. The smaller crystals analysed in EDX7h, are very small $(<1 \mu \mathrm{m} \times 0.1 \mu \mathrm{m})$ and resemble those of 'ball ettringite' reported by other researchers in their studies of cement pastes and mortars [23]. 
Lying directly next to this small ettringite cluster is a number of much larger crystals (ca. $15 \mu \mathrm{m} \times$ $1 \mu \mathrm{m})$. These large AFt crystals were only found in some specimens subject to extended immersion of 14 days. It could be possible that some of these smaller crystals grow preferentially into larger ones. But if this was to be the case, then one would expect to find clusters of very large crystals together, growing in a preferred orientation. This however, was not found, the large crystals were randomly orientated and relatively few found together. 


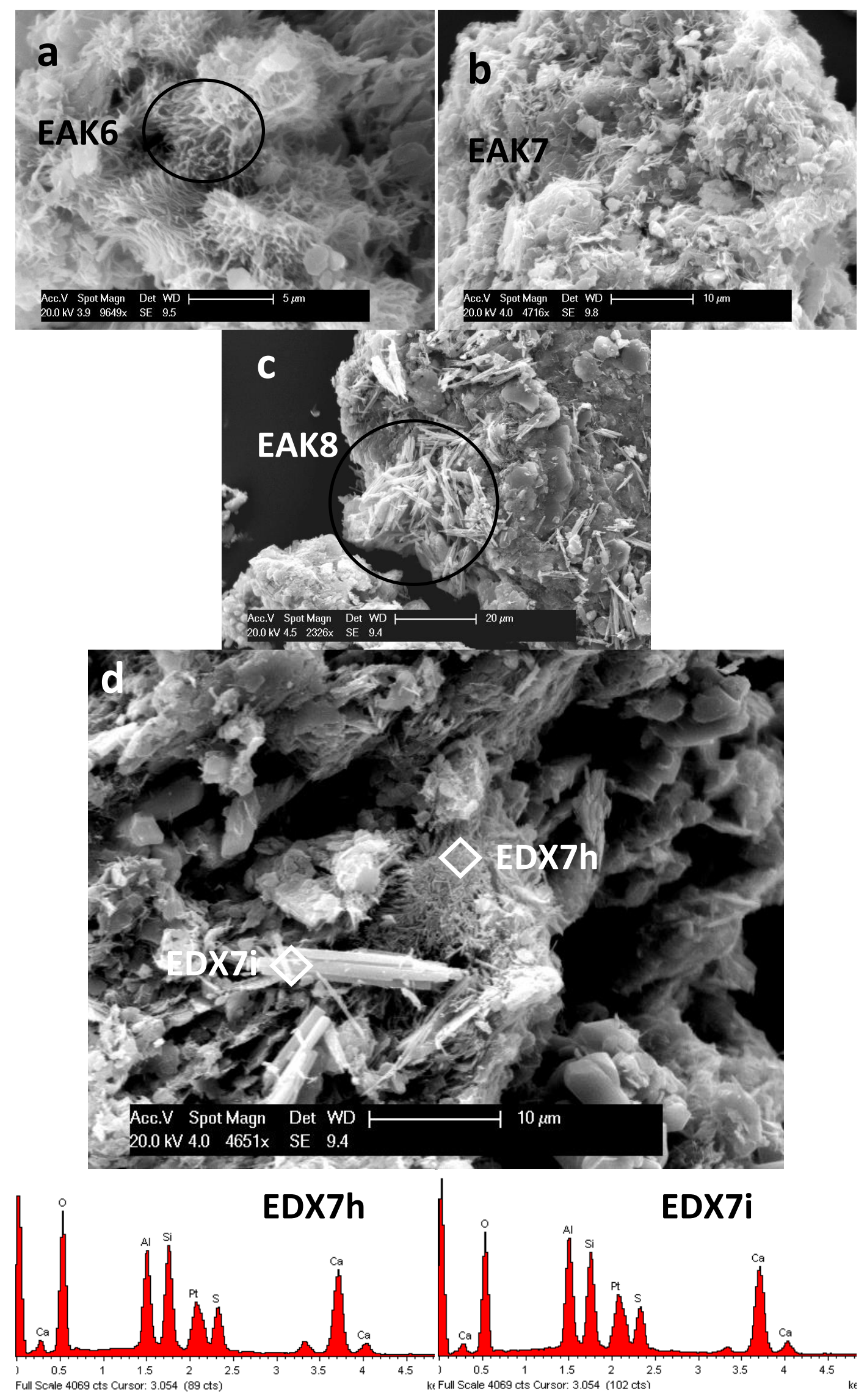


Figure 11: EM micrographs of EAK6 to EAK8 showing AFt formation

High Sulfate Montmorillonite soil (M6L5S)

M6L5S after mixing +1 hour (EAM1) is shown in Figure 12 (a). Small nodules were observed on the clay surface, possibly nucleation sites for ettringite formation. Figure 12 (b) shows M6L5S after conditioning for 24 hours after mixing (EAM2) and as can be seen from the SEM micrographs and EDX point analysis AFt formation is already extensive. EDX7j also shows the AFt crystals to be rich in $\mathrm{Si}$, possibly indicating incorporation of silicon into the structure. Figure 12 (c) shows EAM3 hydrated lime particles in the top left micrograph (circled), while a close-up on the top right shows a primitive $\mathrm{Si}$ rich AFt phase. The crystals are short and stubby but quite thick (ca. $1 \mu \mathrm{m} \times 0.4 \mu \mathrm{m}$ ).

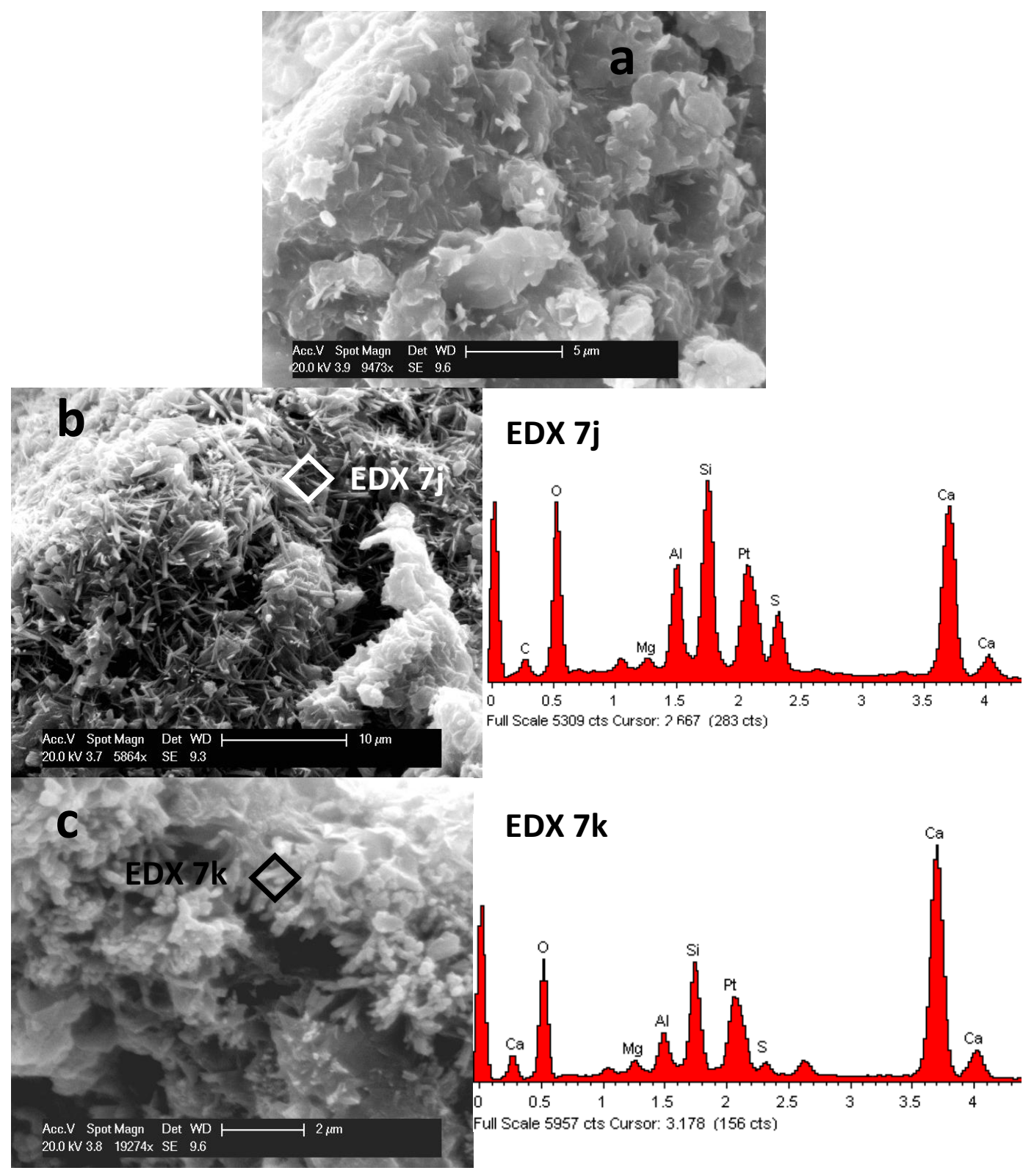


Figure 12: SEM analysis of EAM1 (a) showed small nodules over the clay surfaces which are possibly the very early stages of ettringite nucleation. EAM2 (b) showing extensive ettringite formation EAM2 (c) showing ettringite to be rich in silica

Figure 13 (a) and (b) shows SEM-EDX analysis of EAM4. EDX7I confirms the particle in the top left micrograph to be $\mathrm{CaO}$ (unhydrated lime) due to the very strong emission of $\mathrm{Ca}$ and the largely absent emission of the other elements, although, a small, but probably important emission from $\mathrm{S}$ was found, possibly suggesting dissolution and re-precipitation of gypsum on the surface of the $\mathrm{CaO}$ particle. In the top right micrograph a close-up (circled in both micrographs) of the clay material reveals again a primitive $\mathrm{Ca}$ and Si-rich, AFt phase. The crystals are largely of the same morphology $(1 \mu \mathrm{m} \times 0.4 \mu \mathrm{m})$ as those shown in Figure 12 (c). Figure 13 (c) - (d) shows the progress of AFt formation in the specimens EAM5 to EAM8 (Immersion + 24h to immersion + 14 days). The standout feature when comparing these images is the appearance of discrete, relatively large clusters of AFt ettringite nuclei originating from a central nucleation point (circled). This suggests the material images in the micrographs may well have been part of the void structure of the original material and the crystals were nucleated on the void walls and grew into the pore solution. No discernable differences in the amount of AFt formed could be made out from the SEM-EDX analysis alone. The development of ettringite crystals seemed to be as advanced at EAM5 (immersion $+24 \mathrm{~h}$ ) as it was at EAM8 (immersion+14 days). 

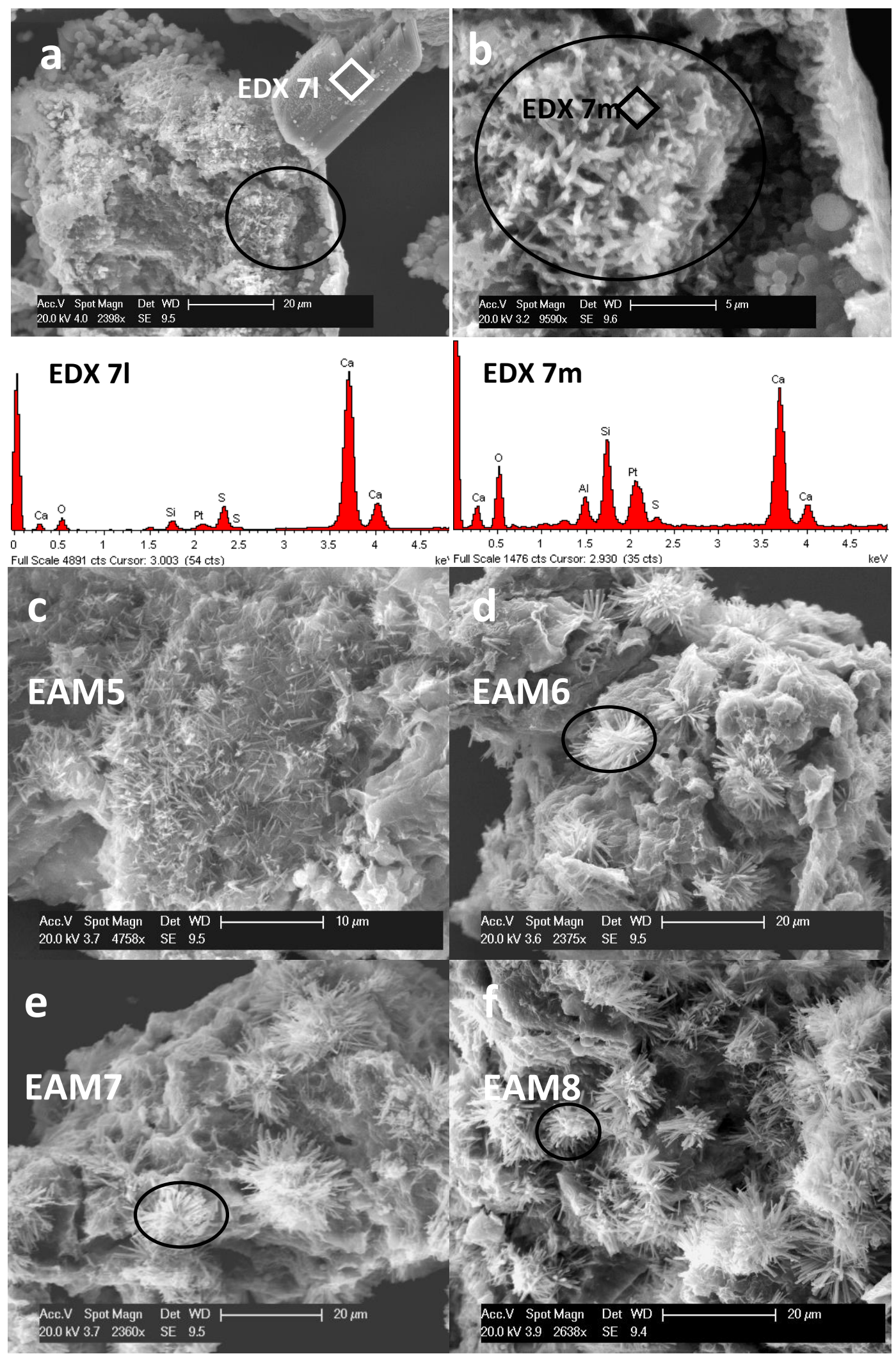

Figure 13: EAM4 showing unhydrated lime particle (a) and close-up circled of primitive Si-rich AFt phase (b), and ettringite formation in samples EAM5 to EAM8 (c) - (d). 


\section{Discussion}

The differing swell response of the two soils presented in Figure 2 is quite significant. Not only in the degree of the volumetric increase $\left(G_{v(\max )} K 4 L 5 S-42 \%\right.$; M6L5S - 15\%) but also the rate of expansion, given that the response of the kaolin soils was largely linear and the montmorillonite curved.

As described earlier, the deleterious volumetric swell can be attributed to the formation of ettringite within the soil matrix and pore solution. The X-ray CT studies showed that the damage to the specimens, observed as cracking of the soil matrix, appeared to start at the surface of the specimen exposed to the immersion water and propagate inwards. This supports the view of Puppala et al. [7]; Ouhadi and Yong [24] and Little et al. [1] that water is a critical factor in AFt formation and its mechanisms of damage. An extensive hydrogen bonding network, in which water is co-ordinated within the AFt column structure, is critical in stabilising the column structures of the ettringite molecule [25]. The increase in the drained specimen water contents over the duration of the test may also indicate an increasing degree of AFt formation, although the greater proportion of the water would be retained in the voids and microcracks that resulted from the swelling, as well as absorption by unreacted clay particles.

Considering the low angle XRD studies, it is surprising that the principal [100] AFt peak at ca. $9.1^{\circ} 2 \theta$ could be detected in EAK2 (mixing $+24 \mathrm{~h}$ ), but was not found in the montmorillonite until EAM5 (immersion+24h). SEM-EDX studies showed that in the kaolin soils, the AFt crystals were very small and difficult to detect by SEM, as they tended towards colloidal size, whereas in the montmorillonite based soils, they were relatively large and well formed, resulting in a greater XRD reflection response. It is suggested that the smaller ettringite crystal size, greater volumetric swell response, coupled with earlier detection by XRD, is evidence of two differing mechanisms of AFt formation at work, namely:

- Topochemical formation and crystal swelling; and

- Through-solution formation and anisotropic crystal growth.

The tendency for ettringite to be formed by one mechanism or the other is dictated by the geochemical thermodynamics of the pore solution, which in turn is controlled by physicochemical drivers such as the reduction in chemical potential; concentration; activities; and diffusivity of the candidate ions [26].

Previous work has shown that the tendency of AFt in a cementitious system to form and expand by one mechanism or the other is dictated by the hydroxide ion concentration (written as $\left[\mathrm{OH}^{-}\right]$in chemistry notation) in the pore solution and its effect on the solubility of the other candidate ions [27] [28].

The formation of larger crystals is favoured when the $\left[\mathrm{OH}^{-}\right]$is low [29] [27]. Within the pore solution this results in lower mobility and hence lower $\left[\mathrm{SO}_{4}{ }^{2-}\right]$ and $\left[\mathrm{Ca}^{2+}\right]$. As a result the $\left[\mathrm{Al}(\mathrm{OH})_{4}{ }^{-}\right]$increases 
and can diffuse into the pore solution before nucleation can occur and is not restricted to the solidsolution interface zone. Few nuclei resulting from slow nucleation rates, grow into large crystals, in both the pore solution and the solid-solution interface zone, and is characterised by the throughsolution mechanism of AFt formation [27] [23]. The results from the analysis of the montmorillonite soils support this. $I_{\max }$ of the AFt [100] from EAM5 onwards is much higher than any of the values measured in the kaolin based soils. In addition ITGA of the soils showed that the thermal event associated with dehydration event of $A F t$ occurred at an average temperature of $98^{\circ} \mathrm{C}$, compared to $90^{\circ} \mathrm{C}$ in the kaolin soils. A greater degree of crystalline order has been shown to increase the temperature that an equivalent thermal event occurs [30], and could be ascribed to the formation of larger crystals .

It would be expected that larger well-formed AFt crystals would give rise to higher diffraction intensities compared to colloidal sized ettringite. Although why no AFt peak could be measured in soils of earlier ages (EAM1-EAM4) is not clear. SEM-EDX analysis of EAM2 showed abundant and well developed AFt crystals. Clusters of quite large AFt crystals growing from a central nucleation point that were found in EAM6 - EAM8 also suggest a slower rate of crystal growth (due to their size). Given that these are still intact and not embedded within the bulk clay, may be evidence that the AFt formed within a pore void from a saturated pore solution, with points on the void structure walls acting as nucleation sites, again suggestive of a through-solution mechanism of formation [31]. Despite extensive AFt formation, which appears to be greater than that found in the kaolin based clays, the overall volumetric swell of the montmorillonite based soils was more than $50 \%$ less. It is generally accepted that when AFt forms by the through-solution mechanism, the overall expansion is less [3133] [1]. This is because the candidate ions for AFt formation can migrate into and form ettringite in the void spaces. Also the larger crystals have a greater specific surface area and thereby small surface energy. Hence, they do not absorb ion and water molecules to the same degree as colloidal ettringite. As such, expansion by crystal swelling is not as significant.

It has been shown that $\left[\mathrm{OH}^{-}\right]$affects the dissolution rate of alumina into the pore solution, and thereby the mechanism of AFt formation and expansion. But the rate of alumina dissolution and its subsequent concentration in the pore solution is also affected by the fundamental structure of the clay itself, because Al sites are more reactive than those occupied by Si. Bauer and Berger [34] in their studies of Kaolinite and Smectite dissolution rates in $\mathrm{KOH}$ solution, suggested that in the montmorillonite, each aluminous octahedral layer is bonded to two silica rich tetrahedral layers. So their exposure to the pore solution is limited to the particle edges, until the tetrahedral layers are dissolved. It follows that given the negligible effect of the edges, compared to the surfaces of the basal planes, the hydrolysis of the octahedral and tetrahedral layer would proceed as a serial reaction, with the overall dissolution rate controlled by the slower step, namely, the dissolution of the tetrahedral layer, given that the strength of the bonds between $\mathrm{Si}$ and $\mathrm{O}(\mathrm{Si}-\mathrm{O})$ are higher than those of $\mathrm{Al}$ and $\mathrm{O}(\mathrm{Al}-\mathrm{O})$ [35]. In contrast, the kaolinite clay has a 1:1 sheet structure of an aluminous octahedral layer bonded to a silica rich tetrahedral layer. As such, more reactive Al sites are exposed 
to the pore solution. Bauer and Berger [34] found dissolution rates for kaolinite to be one or two orders of magnitude higher than for smectitie (the clay group to which montmorillonite belongs).

It follows that when all other conditions are equal, the rate of alumina dissolution and equilibrium concentration within the pore solution will be higher for the kaolin clays than the montmorillonites. Super-saturation of the pore solution with respect to ettringite will occur more rapidly, leading to formation of colloidal size AFt crystals at the solid-solution interface zone. This further supports the experimental evidence for a topochemical ettringite formation and crystal swelling mechanism in kaolin based soils, as opposed to a through-solution and crystal growth mechanism for montmorillonite based soils.

Given the critical role $\left[\mathrm{OH}^{-}\right]$has on the formation, morphology and expansion of ettringite, it would be been valuable to quantify the hydroxide concentration in each soil mix. This could have been achieved by liberating the pore solution by pressure filtration then titrating this against Hydrochloric acid $(\mathrm{HCl})$ using phenlyphaline as indicator. Alternatively simple measurement of the $\mathrm{pH}$ could have been undertaken by calibrating the $\mathrm{pH}$ meter against a range of $\mathrm{KOH}$ solutions, as reported by Winnefield and Lothenbach [36].

\section{Conclusions}

The series of high sulfate soils derived from each clay (K4L5S and M6L5S) were used in a time dependent interval study with the European accelerated volumetric swell test (EN13286-49). Samples (prior to specimen compaction) and specimens were taken at defined intervals and subjected to microscopic and phase composition analysis.

The results show that the kaolin based clays exhibit a greater deleterious swell response than the montmorillonites for the equivalent sulfate content. XRD, dTGA and SEM-EDX analysis found that the ettringite crystals in the kaolin soils were very small and difficult to detect which suggests it preferentially forms and expands by a topochemical and subsequently expands by a crystal swelling mechanism, whereas the ettringite crystals formed in the montmorillonite soil series were comparatively very large suggesting formation by a through-solution and expansion by a crystal growth mechanism. Previous work has shown that the propensity of a cementitious system to form ettringite by one mechanism or the other is dictated by the hydroxide ion $\left[\mathrm{OH}^{-}\right]$concentration in the pore solution:

- High $\left[\mathrm{OH}^{-}\right]$- topochemical and crystal swelling; and

- Low $\left[\mathrm{OH}^{-}\right]$- through-solution and crystal growth.

It is suggested that the much higher cation exchange capacity of the montmorillonite based clay soils results in lower $\left[\mathrm{OH}^{-}\right]$in the pore solution compared to the kaolins where the CEC is lower and results in the maintenance of a much higher $\left[\mathrm{OH}^{-}\right]$. The appearance of much larger ettringite morphologies in the kaolin soils on extended immersion corresponded to a drop in soil $\mathrm{pH}$ (and hence $\left[\mathrm{OH}^{-}\right]$) and 
further supports the view that hydroxide ion concentration of the pore solution within the cementitious matrix affects the mechanistic pathway of AFt formation and expansion. In addition to this, the differing rates of alumna dissolution (as a function of the fundamental clay structure), also reinforce the effect of the Cation Exchange Capacity (CEC). 


\section{References}

[1] Little DN, Nair S, Herbert B. Addressing sulfate-induced heave in lime treated soils. Journal of geotechnical and geoenvironmental engineering. 2009;136(1):110-8.

[2] Mitchell JK, Dermatas D. Clay soil heave caused by lime-sulfate reactions. Innovations and uses for lime. 1992(1135):41.

[3] Hunter D. Lime-induced heave in sulfate-bearing clay soils. Journal of geotechnical engineering. 1988;114(2):150-67.

[4] Perrin L. Expansion of lime-treated clays containing sulfates. Proc, 7th Int Conf on Expansive Soils: ASCE Expansive Soils Research Council New York; 1992. p. 409-14.

[5] Kota PB, Hazlett D, Perrin L. Sulfate-bearing soils: problems with calcium-based stabilizers. Transportation Research Record: Journal of the Transportation Research Board. 1996;1546(1):62-9.

[6] Snedker E, Temporal J. M40 motorway Banbury IV contract-Lime Stabilisation. Highways \& Transportation. 1990;37(12).

[7] Puppala AJ, Griffin JA, Hoyos LR, Chomtid S. Studies on sulfate-resistant cement stabilization methods to address sulfate-induced soil heave. Journal of geotechnical and geoenvironmental engineering. 2004;130(4):391-402.

[8] Rollings MP, Rollings RS. Geotechnical materials in construction: McGraw-Hill New York; 1996.

[9] Cerato AB, Miller G, Elwood-Madden M, Adams A, Varnier MC. Calcium-based stabilizer induced heave in Oklahoma sulfate-bearing soils. Oklahoma: Department of Transportation.(Final Report-FHWA-OK-11-03). ODOT SPR item; 2011.

[10] Basista M, Weglewski W. Chemically assisted damage of concrete: a model of expansion under external sulfate attack. International journal of damage mechanics. 2009;18(2):155-75.

[11] Normalisation CEd. Unbound and hydraulically bound mixturesTest method for the determination of California bearing ratio, immediate bearing index and linear swelling. EN 13286-47 : . London: BSI; 2012.

[12] Normalisation CEd. Unbound and hydraulically bound mixturesAccelerated swelling test for soil treated by lime and/or hydraulic binder. BSI London UK.2004.

[13] Institute BS. BS1924-2 Part 2: Methods of test for cement-stabilized and limestabilized materials. Stabilized materials for civil engineering purposes. London, UK. 1990.

[14] Buttress A, Grenfell J, Airey G. The role of ettringite in the deterioration of artificial lime stabilised soils: a microstructural study. Road Materials and Pavement Design. 2013;14(3):586-614.

[15] Reeves GM, Sims I, Cripps J. Clay materials used in construction. Geological Society of London; 2006.

[16] Murray HH. Traditional and new applications for kaolin, smectite, and palygorskite: a general overview. Applied Clay Science. 2000;17(5):207-21. 
[17] Cripps J, Taylor R. The engineering properties of mudrocks. Quarterly Journal of Engineering Geology and Hydrogeology. 1981;14(4):325-46.

[18] Normalisation CEd. BS EN 14227-11. Unbound and hydraulically bound mixtures Specifications Soil treated by lime. BSI London UK.2006.

[19] Schmid B. ImageJ 3D viewer. cited; 2009.

[20] Möschner G, Lothenbach B, Rose J, Ulrich A, Figi R, Kretzschmar R. Solubility of Fe-ettringite $(\mathrm{Ca}<$ sub $>6</$ sub $>[\mathrm{Fe}(\mathrm{OH})<$ sub $>6</$ sub $>]<$ sub $>2</$ sub $>(\mathrm{SO}<$ sub $>$ $4</$ sub $>$ ) $<$ sub $>3</$ sub $>.26 \mathrm{H}<$ sub $>2</$ sub $>0$ ). Geochimica et Cosmochimica Acta. 2008;72(1):1-18.

[21] Goetz-Neunhoeffer F, Neubauer J, Schwesig P. Mineralogical characteristics of Ettringites synthesized from solutions and suspensions. Cement and Concrete Research. 2006;36(1):65-70.

[22] Cody A, Lee $H$, Cody R, Spry P. The effects of chemical environment on the nucleation, growth, and stability of ettringite $[\mathrm{Ca}<\mathrm{sub}>3</$ sub $>\mathrm{Al}(\mathrm{OH})<$ sub $>6</$ sub $>]<$ sub $>2</$ sub $>(\mathrm{SO}<$ sub $>4</$ sub $>)<$ sub $>3</$ sub $>\cdot 26 \mathrm{H}<$ sub $>2</$ sub $>0$. Cement and Concrete Research. 2004;34(5):869-81.

[23] Tosun K, Baradan B. Effect of ettringite morphology on DEF-related expansion. Cement and concrete Composites. 2010;32(4):271-80.

[24] Ouhadi VR, Yong RN. Ettringite formation and behaviour in clayey soils. Applied Clay Science. 2008;42(1):258-65.

[25] Hartman M, Berliner R. Investigation of the structure of ettringite by time-of-flight neutron powder diffraction techniques. Cement and Concrete Research. 2006;36(2):36470.

[26] Gartner EM, Macphee DE. A physico-chemical basis for novel cementitious binders. Cement and Concrete Research. 2011;41(7):736-49.

[27] Min D, Mingshu T. Formation and expansion of ettringite crystals. Cement and Concrete Research. 1994;24(1):119-26.

[28] Wang L, Roy A, Seals RK, Byerly Z. Suppression of sulfate attack on a stabilized soil. Journal of the American Ceramic Society. 2005;88(6):1600-6.

[29] Cohen M. Theories of expansion in sulfoaluminate-type expansive cements: schools of thought. Cement and Concrete Research. 1983;13(6):809-18.

[30] Guggenheim S, Van Groos AK. Baseline studies of the clay minerals society source clays: thermal analysis. Clays and Clay Minerals. 2001;49(5):433-43.

[31] Soroka I. Portland cement paste and concrete: Macmillan London; 1979.

[32] Kalousek G, Benton EJ. Mechanism of seawater attack on cement pastes. Am Concrete Inst Journal \& Proceedings. 1970.

[33] Dermatas D. Ettringite-induced swelling in soils: State-of-the-art. Applied Mechanics Reviews. 1995;48(10):659-73.

[34] Bauer A, Velde B. Smectite transformation in high molar $\mathrm{KOH}$ solutions. Clay Minerals. 1999;34(2):259-73. 
[35] Mantovani M, Escudero A, Alba M, Becerro A. Stability of phyllosilicates in $\mathrm{Ca}(\mathrm{OH})<$ sub> 2</sub> solution: Influence of layer nature, octahedral occupation, presence of tetrahedral Al and degree of crystallinity. Applied Geochemistry. 2009;24(7):1251-60.

[36] Winnefeld F, Lothenbach B. Hydration of calcium sulfoaluminate cementsexperimental findings and thermodynamic modelling. Cement and Concrete Research. 2010;40(8):1239-47. 